\title{
LARGE SCALE PROCESSING OF SEISMIC DATA IN SEARCH OF REGIONAL AND GLOBAL STRESS PATTERNS
}

\author{
By A. Ben-Menahem, H. Jarosch and M. Rosenman
}

\section{ABSTRACT}

A composite computer program has been devised for a fast reduction of multistation seismic data in the period range $50-500 \mathrm{sec}$ for mantle surface waves and 20-100 sec for body waves.

The analysis aims at the reconstruction of the seismic source from the spectrum of its far radiation field and the correlation of its parameters with its depth, size and regional environment.

The capability of the computational procedure has been demonstrated in two studies of WWNSS records: one includes a spectral analysis of surface waves from a shallow shock in the Kurile Islands; the other includes a spectral analysis of $P$ waves from 9 shocks in the depth range $550-700 \mathrm{~km}$ at Fiji, Mariana, Java, Japan, Peru and Brazil.

Other applications of the proposed data processing routine are foreseen; a tsunami warning system and focal depth determination from spectral modal ratios.

It is believed that a persistent search for stress patterns, based on the processing of a sufficiently large sample of seismic events, is essential to any future program of earthquake prediction.

\section{INTRODUCTION}

A major problem in seismology is the development of dependable numerical procedures for the extraction of source information from the various seismic signals.

Chief among them is the spectral equalization method. (Satô, 1955; Tukey, 1959; Aki, 1960; Brune, 1961; Ben-Menahem and Toksöz, 1963; Kasahara, 1963; Toksöz, Ben-Menahem and Harkrider, 1964). According to this method one isolates on the seismogram certain wave forms which correspond to seismic rays or modes. These wave forms are separated from the records, transformed into digital form and then subjected to a Fourier analysis. The spectrums are then compensated for whatever "happened" to them on their routes from the source to the stations. Effects such as dispersion, attenuation and instrumental distortion are taken into account. Finally, one compares the amplitude and phase residuals with theoretical source models in order to determine the physical parameters of the source. (Ben-Menahem, 1961; Haskell, 1963; Ben-Menahem and Harkrider, 1964; Brune, 1964; Ben-Menahem, Smith and Teng, 1965; and Aki, 1966).

This equalization procedure is applicable to the entire spectral range from body waves of 20 second period to periods of the order of one hour. (Alsop and Brune, 1965; Teng and Ben-Menahem, 1965).

Recent studies in this particular field have furnished us with an incomplete picture of the seismic source. Most of these previous studies were based on data from a single seismic event. Since the establishment of a world-wide network of standard stations by the USCGS, studies have been made of single events around a network of stations. However, in order to obtain a fuller understanding of the nature of the seismic source, it would be extremely helpful to study many earthquakes from many regions, achiev- 
ing through the resulting distribution of events a much firmer basis for the drawing of more general conclusions regarding the mechanism of earthquake sources.

We shall now turn to a detailed description of the computational procedure.

\section{ANALYSIS OF SURface Waves}

With the aid of modern ultra long-period seismographs it now becomes possible to record mantle Rayleigh and Love waves from shocks with a Richter magnitude that is as low as $5 \frac{1}{2}$ (Figure 1). Had the WWNSS been equipped with seismographs of this kind, the present suitable data for source studies would have increased by a factor of at least ten. With the recordings of the WWNSS, however, we must restrict ourselves to magnitudes higher than 7 . For lower magnitudes it is difficult to obtain a good azimuthal coverage for most source locations.

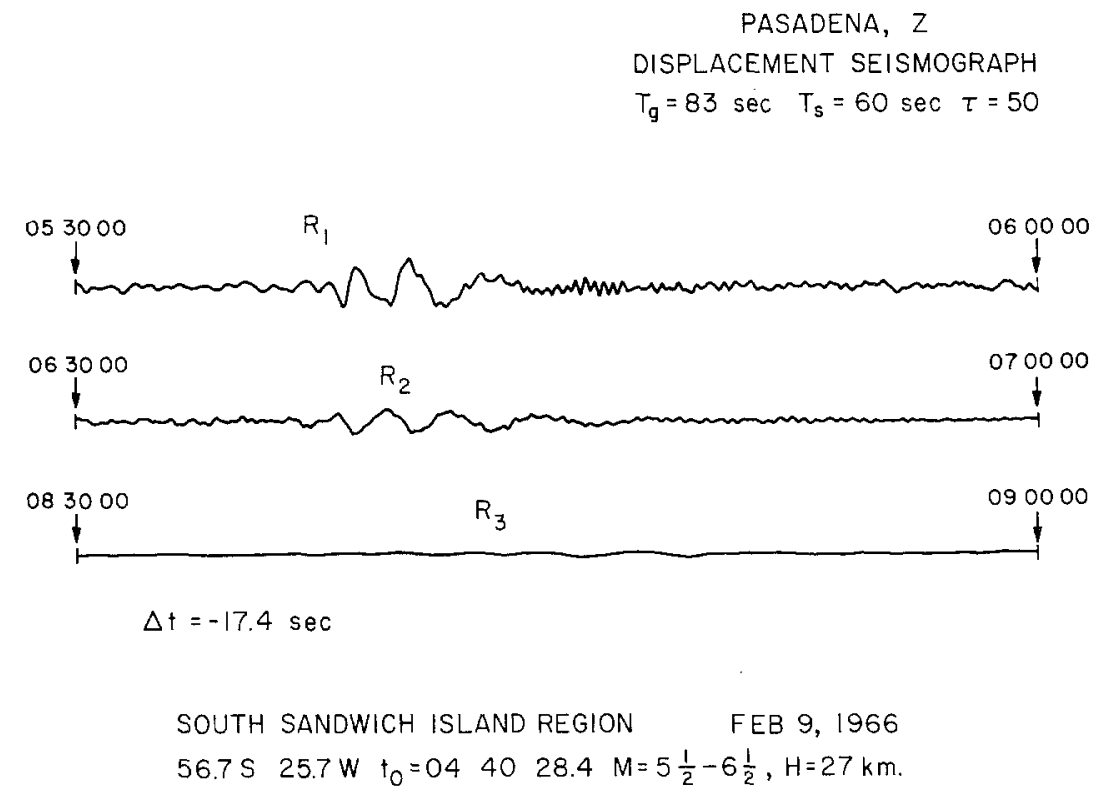

Fig. 1. Displacement seismograms of mantle Rayleigh waves from an earthquake in the intermediate magnitude range. (By courtesy of Mr. Ralph Gilman and Dr. Stewart W. Smith, California Institute of Technology, Pasadena, California.)

Let us therefore assume the availability of a readable set of long-period seismograms with a fair azimuthal coverage. Assume also that the origin time, the source coordinates and the source depth are known, and that the relevant Rayleigh and Love signals have been separated from the records and digitized. To speed up the identification and separation of the various signals from the records, we found it quite useful to prepare a routine which prints for each station "arrivals" and "departures" of Love and Rayleigh waves, corresponding to a few chosen group velocity windows.

Figure 2 summarizes the chain of operations relevant to the first stage of the data analysis. Let a time-interval on the seismogram be represented by the function $\left\{f(t) \cdot I\left(t_{0}, t_{1}\right)\right\}$ where $I=1$ for $t_{0}<t<t_{1}$, and $I=0$ for $t_{1}<t$ and $t<t_{0}$. Its Fourier transform (the trace spectrum) was defined by us as

$$
F(\omega)=\int_{t_{0}}^{t_{1}} f(t) e^{-i \omega t} d t
$$


Using the modified trapezoid rule to evaluate the integral the program then prints amplitudes, phases, normalized amplitudes and log (amplitudes) for any specified set of frequencies. The program was designed with multi-station input data in mind, namely, with the object of minimizing the visual and manual labor of the research staff by letting the computer do most of the routine work, including simple decisions.

The output of the first stage is obtained simultaneously in two forms: (1) as com-

SURFACE WAVE ANALYSIS PROGRAM

PT. I - FOURIER OR POWER SPECTRUM ANALYSIS
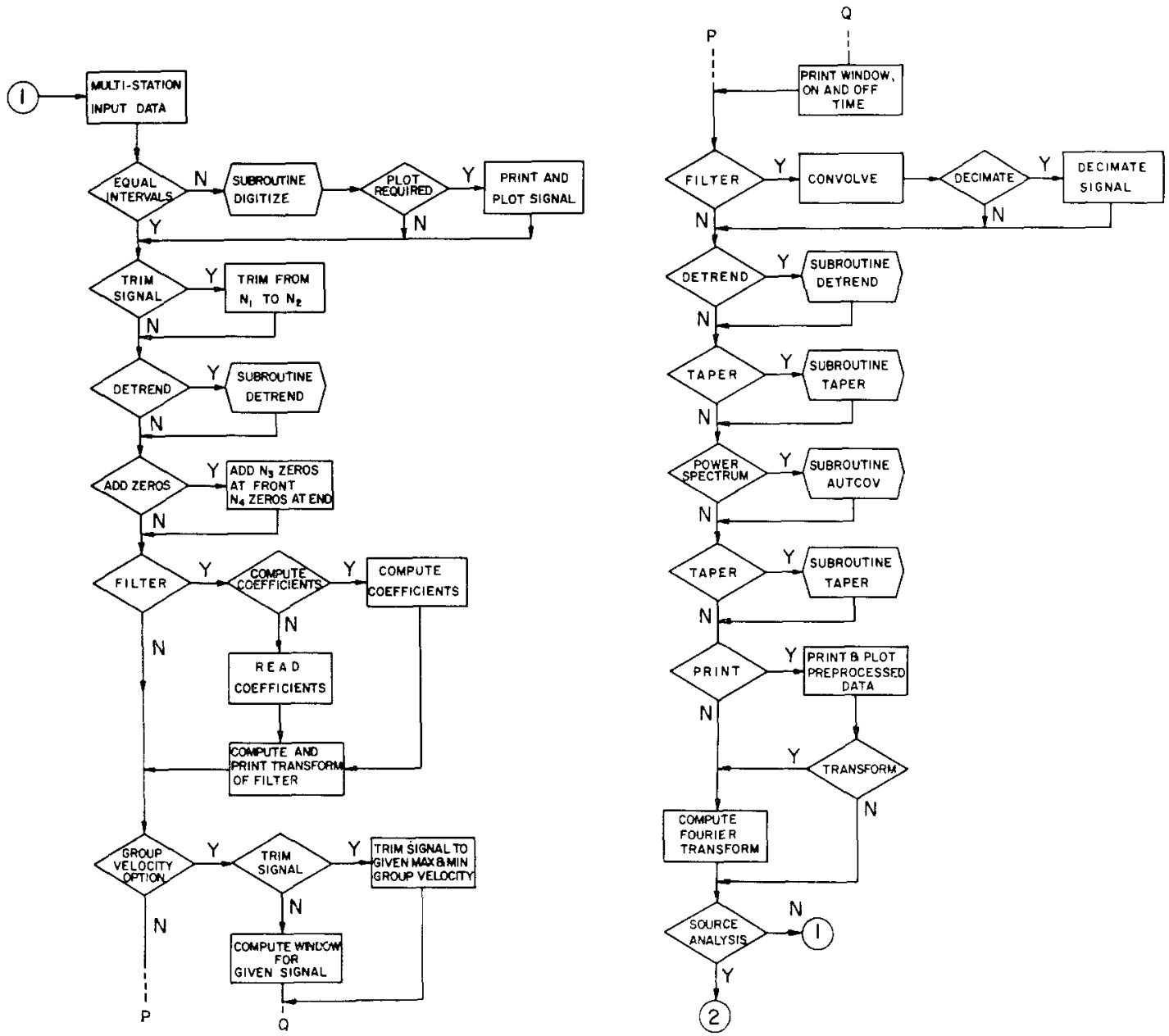

Frg. 2. Flow diagram for a routine Fourier analysis of multi-station seismic data. $\mathrm{Y}=\mathrm{YES}$, $\mathrm{N}=$ NO. Connections (1) and (2) lead to Figures 3 and 14.

puter sheets on which the trimmed, detrended, filtered and tapered (if so required) signals are plotted and their Fourier spectrums tabulated and plotted, and (2) as tape or card output carrying the same information.

This output serves as the input to the second stage, which is summarized in Figure 3. The reader should keep this scheme in mind while we explain its details in the subsequent figures.

The theoretical background of the equalization method is as follows: 
The source is assumed to be specified as a product of three factors:

(1) the spatial factor, which depends upon the equivalent force system;

(2) the temporal factor, which is the Fourier transform of the source time function;

(3) the finiteness factor, which arises from the hypothesis that the rupture along the fault moved horizontally with a uniform speed over a finite distance.

The spatial factor, like the other two factors, is complex; it is determined by the orientation of the source, its depth, and the structure of the layered medium through which the signal propagates. As the signal spreads out on its way to the recording station, its spectrum is modified by:

SURFACE WAVE ANALYSIS PROGRAM PART II - SOURCE MECHANISM

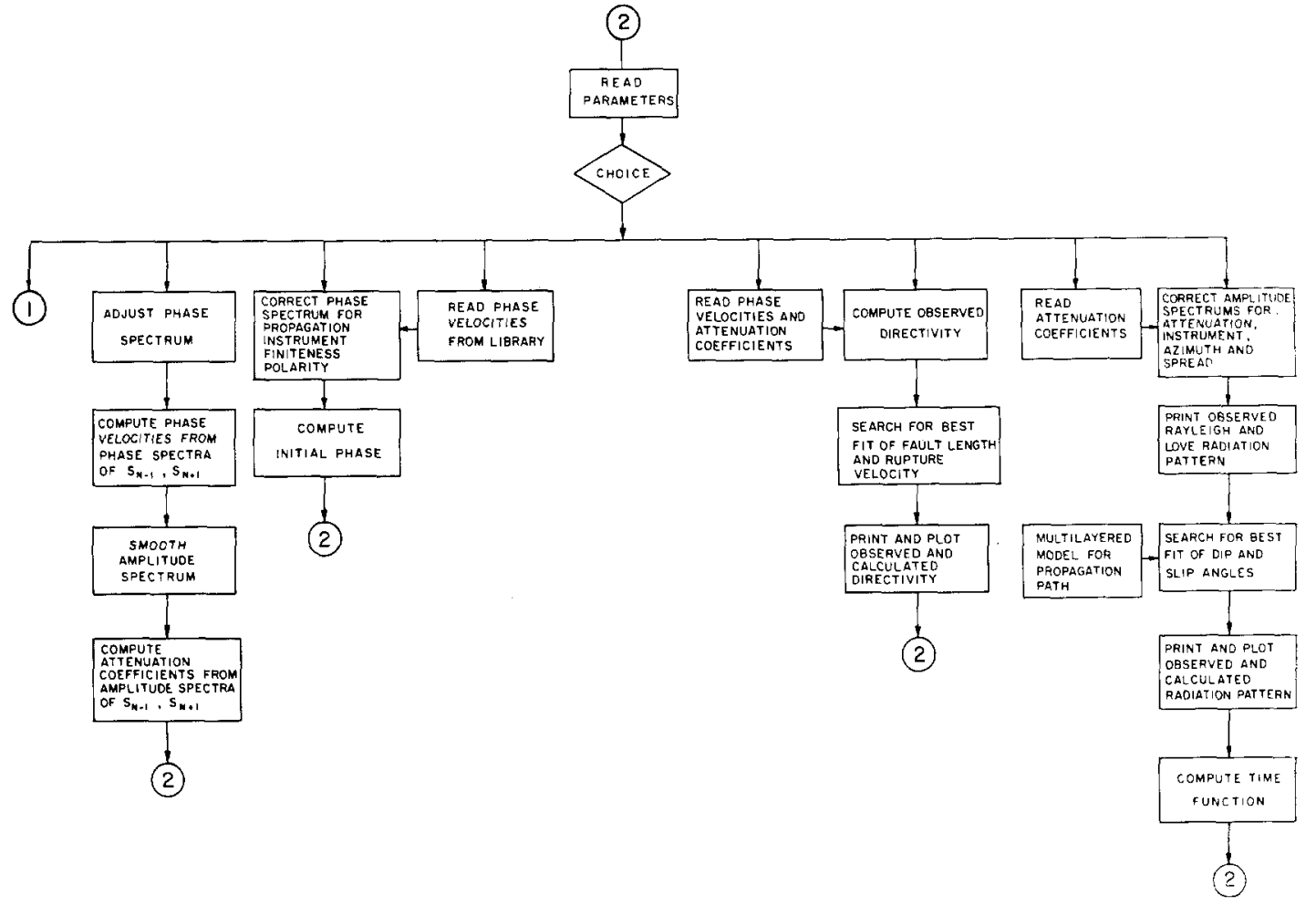

FIG. 3. Flow diagram for quasi-automatic derivation of source parameters from multi-station surface wave data.

(1) attenuation due to the inelasticity of the upper mantle;

(2) dispersion, geometrical spread, and polar phase shift over a spherical Earth; and

(3) the filtering and directional effects of the recording instrument.

The compensation for these distorting agents is known as the amplitude and phase equalization of the signal's spectrum.

In the case of earthquakes which exhibit multiple arrivals of both even and odd orders, the "directivity method" can be used to determine the fault length and the rupture speed (if any) from records of a single station. A ratio of spectra of even and odd arrivals is fitted to theoretical curves for various combinations of fault length and rupture speed. This ratio, known as the directivity, can perhaps be better visualized if one imagines the radiation field of a moving antenna of finite length. The spectral 
ratio of the forward to the backward fields is diagnostic of the radiator's length and speed.

Once the source parameters have been determined from the directivity, an immediate comparison is made with the extent of the aftershock zone. Previous results indicate that there is some relationship between the "directivity fault length" and the aftershock extent.

The phase equalization method can be used only if the phase velocities over the

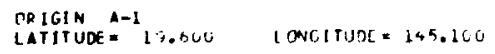

\begin{tabular}{|c|c|c|c|c|c|c|c|}
\hline STATION & LATITIJDE & LONEITUNE & DII MUTH & INV.AZIMUTH & DISTIOEC, & DISTIKMI & CIRCLE \\
\hline$\frac{-1}{f, U A *}$ & 19.600 & 145.160 & 0 & 0 & 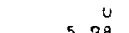 & 0 & 40009.15 \\
\hline $\begin{array}{l}\text { GUA* } \\
\text { MAT* }\end{array}$ & $\begin{array}{l}13.588 \\
36.542\end{array}$ & $\begin{array}{l}144.912 \\
138.219\end{array}$ & $\begin{array}{l}181.78 \\
341.71\end{array}$ & $\begin{array}{r}1.70 \\
=.844\end{array}$ & $\begin{array}{r}5.38 \\
17.93\end{array}$ & $\begin{array}{r}0.05 .06 \\
1904.47\end{array}$ & $4 \operatorname{coc} 9.21$ \\
\hline SHK & 34.530 & $\begin{array}{l}138.229 \\
132.678\end{array}$ & 325.98 & 140.79 & 18.51 & $\angle C 5 A .85$ & 40028.23 \\
\hline ANP* & 25.183 & 121.517 & 288.51 & 99.56 & 22.49 & 2502.2 .3 & 40003.34 \\
\hline SAV* & 7.088 & 125.575 & 239.38 & 54.83 & 22.67 & 2523.47 & 40053.20 \\
\hline MAN* & 14.667 & $121.0 \times 3$ & $2 t 1.68$ & 74.55 & $23.4 A$ & 2610.79 & 40067.79 \\
\hline BAG* & 10.411 & 120.540 & $2+6.20$ & 78.50 & 23.53 & 2018.38 & 40000.86 \\
\hline SE O* & 37.567 & 125.967 & 322.35 & 133.55 & 23.88 & 2056.57 & 46031.75 \\
\hline $\begin{array}{l}\text { RAB B } \\
\text { PMG* }\end{array}$ & -4.193 & 152.171 & $162.8 E$ & 343.04 & 24.54 & 2743.22 & 40014.26 \\
\hline $\begin{array}{l}\text { PMG* } \\
\text { HKC }\end{array}$ & -9.409 & 147.154 & 175.80 & 355.99 & 88.90 & 3216.53 & 40009.47 \\
\hline $\mathrm{HKC}$ & 22.304 & 114.172 & 280.81 & 89.57 & 28.98 & 3225.14 & 40067.15 \\
\hline$H N R *$ & -9.432 & 159.947 & 151.80 & 333.16 & 32.34 & $36 c 0.30$ & $4 \cup \cup 22.38$ \\
\hline DAR & -12.383 & 130.8 .3 & 264.99 & 24.06 & 34.75 & 3867.97 & 4 4uig. 73 \\
\hline MHAN & 12.210 & 109.212 & 263.43 & 73.33 & 35.73 & 3921.24 & 40600.20 \\
\hline $\operatorname{cta*}$ & $-20.08 \mathrm{H}$ & 146.254 & 178.29 & 358.29 & 39.46 & 4392.09 & 4 cuU9.21 \\
\hline CHG & 18.796 & 98.977 & $276.9 ?$ & P1.GB & 43.48 & 4836.66 & $40008 .<5$ \\
\hline$A O A$ & 51.863 & -170.055 & 33.63 & 237.34 & 43.88 & 4879.19 & $46 \cup 27.55$ \\
\hline SNG. & 7.173 & 1100.020 & 260.28 & 69.47 & $44 . R A$ & 4792.49 & 40007.31 \\
\hline LEM* & -0.833 & 107.017 & 238.23 & 53.82 & 45.29 & 5041.97 & 40052.29 \\
\hline BND & -0.900 & 107.650 & 238.13 & 53.75 & $4^{5} \cdot 31$ & 5043.25 & 40052.20 \\
\hline MOU & -22.310 & 160.451 & 152.35 & 331.80 & 46.59 & 5185.33 & $46 u 21.96$ \\
\hline SHL $*$ & $25.5 \times 7$ & 91.483 & 267.23 & 85.54 & 49.23 & 5477.63 & 40063.87 \\
\hline HOW & 32.417 & 45.309 & $2 \notin 3.68$ & 91.86 & 52.83 & 5877.96 & 40063.15 \\
\hline KIP* & 21.423 & $-158.01=$ & 77.53 & 278.90 & 53.06 & 5904.01 & 40060.31 \\
\hline$R$ IV* & -33.829 & 151.159 & 173.72 & 352.82 & 53.44 & 5947.77 & 40009.80 \\
\hline Af 1 . & -13.909 & -171.777 & 124.81 & 307.14 & 53.95 & 6004.133 & 40045.39 \\
\hline ADE* & -34.967 & $138.7: 9$ & 196.44 & 7.40 & $54 . t C$ & 6076.82 & G0u04. 90 \\
\hline MUN* & -31.975 & 110.227 & 208.97 & 32.38 & $5 R \cdot 2 B$ & 6486.23 & 46023.63 \\
\hline PIO & 71.133 & $-15 n . A=0$ & 18.32 & 245.63 & 61.49 & 6832.43 & 46015.66 \\
\hline NO1* & 28.083 & 77.217 & 202.60 & 81.95 & 61.90 & 6085.64 & 40060.18 \\
\hline TAU* & -42.910 & 147.320 & 178.10 & 357.63 & 62.23 & 6924.66 & 40069.21 \\
\hline $\operatorname{coc}$ & 64.900 & -147.703 & 20.23 & 257.60 & $t 2.74$ & 6972.59 & 40020.84 \\
\hline LAHE & 31.550 & 74.333 & 298.23 & A 2.13 & 63.97 & 7116.36 & 40037.36 \\
\hline$K O D$ & 10.233 & $77.4+7$ & 272.61 & 73.10 & 55.67 & 7308.65 & $4006 \mathrm{H} .94$ \\
\hline WFL. & -41.287 & $174.7+7$ & 156.01 & 329.42 & 65.54 & 7404.03 & 40019.00 \\
\hline 9000 & 18.533 & 73.850 & 282.32 & 76.12 & 66.97 & 74410.47 & 40060.34 \\
\hline$R \wedge R *$ & -21.217 & -150.773 & 124.04 & 303.14 & 67.48 & 7511.26 & 40050.18 \\
\hline OUf* & $30.1 \% 8$ & 60.956 & 209.95 & 78.25 & 70.46 & 7837.79 & $400,7.57$ \\
\hline$P P T$ & -17.533 & -149.583 & 119.59 & 296.98 & 73.99 & 8235.89 & 40057.01 \\
\hline MSH. & 36.311 & $50.58 \mathrm{~A}$ & 343.59 & 76.47 & 75.16 & 3358.24 & $4 \cos 0.08$ \\
\hline $\mathrm{CHC}$ & 67.833 & $-115 \cdot \operatorname{CA} 3$ & 22.71 & 25.6 .50 & 75.57 & $9407.3 \mathrm{~B}$ & 4CU1H. CS \\
\hline roan & 44.580 & $-123.3 \times 3$ & 47.00 & 285.23 & 77.61 & $162 R .91$ & $4 C 641.14$ \\
\hline InNe & 46.750 & -121.910 & 44.58 & 285.79 & 79.04 & $A \in 76.0 B$ & 40030.01 \\
\hline NOR* & 81,000 & $-10 . \cos 3$ & 357.31 & 17.50 & 79.57 & 8727.39 & 46049.28 \\
\hline Ax s. & 37.877 & -122.225 & 53.33 & 287.15 & 80.26 & ค224. P4 & 40047,61 \\
\hline$K \in V$ & 64.757 & 27.015 & 341.98 & 57.39 & RU. 36 & 9997.44 & 40014.92 \\
\hline XTC* & 70.417 & $21.0 \times 3$ & 343.43 & 32.49 & 81.94 & 9102.13 & 40014.01 \\
\hline tec. & 77.167 & $-61.1+3$ & 5.72 & 325.13 & 82.10 & 8124,47 & soweriss \\
\hline SNI: & 29.644 & 32.526 & 248.74 & 71.72 & 82.69 & 9197.34 & $40 u 55 \cdot 16$ \\
\hline TAB & 38.675 & 46.377 & 360.00 & 69.31 & 04.55 & 9401.21 & 46045.26 \\
\hline PAS & 34.148 & $-118.17 ?$ & $=5.83$ & $269.9 \mathrm{~A}$ & 84.57 & 9404.34 & 46050.10 \\
\hline$B O Z *$ & 45.600 & -111.033 & 43.30 & 292.93 & $B 5.00$ & 9458.84 & $400+7.26$ \\
\hline $\csc$ & 35.302 & -116.015 & 54.35 & 290.51 & 85.23 & 9477.26 & $4004 H_{1} 65$ \\
\hline PLA* & 33.353 & - 11 t. At 2 & 56.19 & 290.02 & 85.86 & 9549.84 & $4005 i .45$ \\
\hline DUG. & 40.195 & -112.513 & 49.63 & 292.52 & 86.38 & 9603.74 & 40042.83 \\
\hline
\end{tabular}

Fig. 4. A computer output of a distance-azimuth subroutine for a network of WWNSS.

great circle path from the source to the station are known. If the path is mostly continental or purely oceanic, appropriate phase velocities must be employed. The essence of this method is basically a careful "bookkeeping" of the phase history of the signal. The thumb rule is, that all phase advances due to propagation, sphericity, source to station geometry and instrumental distortion, must be subtracted, and all phase retardations (such as the initial phase due to time dependence and finiteness) must be added to the phases of the Fourier analysis. The algebraic signs of the Fourier phases depend upon whether the Fourier transform has been performed with $e^{i \omega t}$ or $e^{-i \omega t}$. 
Once the phases have been stripped of everything which "happened to the signal on its way to the station", interpretation in terms of source elements begins. Theoretically, for the horizontal component of displacement due to a point source, the sum of the spatial phases of two opposite-going signals must (for a shear fault) be exactly equal to $\pi / 2$. If the source is of the propagating rupture type, the sum will be equal to $\pi / 2-\tau f$, where $f$ is the frequency and $\tau$ is the time of rupture.

Next, the remaining phases are explained in terms of the orientation angles of a displacement vector at the source. This is done with the aid of an inversion program which calculates theoretical phase spectrums for various orientations and depths in a multilayered flat earth model.

Figure 4 shows a typical output sheet which gives the necessary geometrical distances and angles from the source to the recording station network.

Figure 5 shows a sample of the amplitude equalization procedure. The second and

\begin{tabular}{|c|c|c|c|c|c|c|c|}
\hline & & & & ED & & $M$ & \\
\hline+111 & & PER [OD & & $\triangle M P(N 1, I)$ & & $\triangle T T$ & \\
\hline $5.0000 F$ & -3 & $2.0000 \mathrm{~F}$ & 2 & $5.6468 E$ & 3 & $2.9018 \mathrm{E}$ & -1 \\
\hline $5.2000 F$ & -3 & $1.9231 \mathrm{E}$ & $?$ & $5.940 \mathrm{FT}$ & 3 & $2.6293 E$ & -1 \\
\hline $5.4000 E$ & -3 & $1.8519 \mathrm{f}$ & $?$ & $5.9812 E$ & 3 & 2.39075 & -1 \\
\hline $5.6000 E$ & -3 & $1.7957 \mathrm{~F}$ & $?$ & $5.6874 \mathrm{E}$ & ? & $2.2657 E$ & -1 \\
\hline 5. $\mathrm{AOOCF}$ & $-x$ & $1.7241 \mathrm{E}$ & 7 & $5.3730 \mathrm{~F}$ & $x$ & $2 . \mathrm{C} 522 \mathrm{~F}$ & -1 \\
\hline $5.0000 \mathrm{~F}$ & $-?$ & $1.0667 E$ & 3 & $5.3742 \mathrm{~F}$ & 3 & $31 \mathrm{~F}$ & -1 \\
\hline $.2300 \mathrm{~F}$ & -3 & $1.6120 \mathrm{~F}$ & i & $5.7510 \mathrm{~F}$ & 3 & $1.9588 \mathrm{~F}$ & -1 \\
\hline $.4000 \mathrm{~F}$ & -3 & $1.50 ? 5 \mathrm{~F}$ & $?$ & $6.269 C 5$ & 3 & 1.08365 & -1 \\
\hline E. $6900 \mathrm{~F}$ & -3 & $1.5152 \mathrm{t}$ & $?$ & $6.6155 \mathrm{E}$ & & $1.6023 \mathrm{~F}$ & -1 \\
\hline $.8000 \mathrm{~F}$ & -3 & $1.470 \mathrm{OE}$ & ? & $5.628 ? 5$ & 3 & $1.2912 F$ & -3 \\
\hline $0 J 0 E$ & -3 & $1.4286 E$ & ? & 0.38155 & & $1.10 C 7 \mathrm{~F}$ & -1 \\
\hline $000 \mathrm{~F}$ & -3 & $1.3989 \mathrm{E}$ & $\because$ & $3.0401 E$ & 3 & $1.1907 \mathrm{~F}$ & -1 \\
\hline$O E$ & -3 & $514 \mathrm{E}$ & ? & 155 & 3 & $1907 \mathrm{~F}$ & -1 \\
\hline DUE & -3 & $158 E$ & $?$ & $5.2484 \%$ & 3 & $1332 \mathrm{~F}$ & -1 \\
\hline gone & -3 & $1.2 B ? 1 E$ & $?$ & $4.505 \leq F$ & $?$ & $9.7683 E$ & -2 \\
\hline B. $0000 \mathrm{E}$ & -.3 & $1.250 \cap \mathrm{F}$ & $?$ & $3.6169 \mathrm{~F}$ & 3 & $1.0264 F$ & -1 \\
\hline B. $2000 \mathrm{E}$ & -3 & $1.2105 \mathrm{~F}$ & $?$ & $2.8507 \mathrm{~F}$ & 3 & 1. $\mathrm{Cl}_{3}^{38 \mathrm{~F}}$ & -1 \\
\hline 0005 & -3 & $1.1995 \mathrm{E}$ & , & $2.5042 F$ & 2 & $1.0013 \mathrm{~F}$ & -1 \\
\hline$B .6000 E$ & -3 & $628 F$ & 2 & $6346 !$ & 2 & $0.8999 \mathrm{~F}$ & -2 \\
\hline OOE & -3 & $364 \mathrm{E}$ & $?$ & $9384 \mathrm{~F}$ & 3 & $9.76 R 3 F$ & -2 \\
\hline $9.0000 \mathrm{E}$ & -3 & 1111 & $i$ & $.1123 t$ & 3 & $0.4124 \mathrm{~F}$ & -2 \\
\hline $9.2000 E$ & -3 & 1. $6870 E$ & 2 & $3.1004=$ & 3 & $0 . n 694 \mathrm{~F}$ & -2 \\
\hline $.4030 F$ & -3 & $1.0638 \mathrm{~F}$ & ? & 3. CG BR.F & 7 & p.739 gr & -7 \\
\hline $300 F$ & -3 & $1.0417 \mathrm{E}$ & $?$ & $3.0+355$ & 2 & $5.4 ? \cdot \mathrm{st}$ & -2 \\
\hline & -3 & $? ? 4 \mathrm{E}$ & $i$ & $3 . n 68=F$ & 3 & 7. R $1 \times 1 \mathrm{~F}$ & -2 \\
\hline $030 F$ & -2 & E J J & ? & .15031 & 3 & $7.7597 F$ & -2 \\
\hline
\end{tabular}

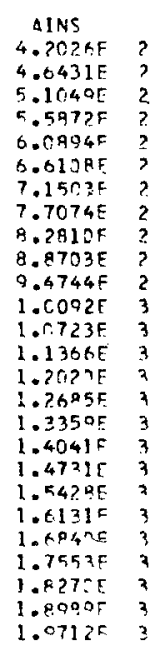

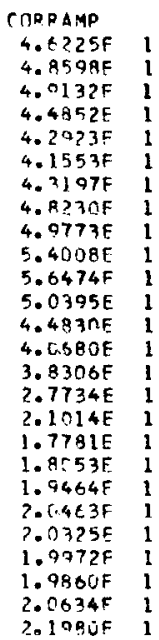

Fig. 5. A computer output for amplitude equalization of surface wave signals from a network of WWNSS. The particular result shown here is for a Rayleigh wave $R_{3}$ recorded at Aquila, Italy from the Kurile Islands aftershock of October 20, 1963.

third columns from the left list the frequencies and the periods, respectively. The fourth column lists the Fourier amplitude spectrum over the given frequency range. Next is the physical attenuation factor $e^{-\gamma(\omega) \Delta}$ where $\gamma(\omega)$ is the frequency dependent attenuation factor, and $\Delta$ is the central angle in radians from station to epicenter.

The column AINS lists the amplitude response of a critically damped and zerocoupled WWNSS seismograph system:

AINS $(\omega)=M \omega^{3} /\left(\omega_{0}^{2}+\omega^{2}\right)\left(\omega_{g}^{2}+\omega^{2}\right)$

where $M$ is a constant pertinent to the magnification at the recording station. Explicitly $M \simeq M_{0} \omega_{0}$ where $M_{0}$ takes one of the values: $6000,3000,1500,750,375$. For a general reference see Hagiwara (1958).

Finally

$$
\text { COR RAMP }=\frac{(\mathrm{AMP})(\mathrm{INV} \cdot \mathrm{AZC} \emptyset \mathrm{R})}{(\mathrm{ATT})(\mathrm{AINS})} \sqrt{\sin \Delta}
$$

Letting INV.AZ be the inverse azimuth at the station, measured clockwise from 
north, then

INV.AZCØR $=1$ for $U_{z}$ (vertical displacement) at all angles.

$$
\begin{aligned}
& =\frac{1}{\sin (\mathrm{INV} . \mathrm{AZ})} \text { for } N S \text { Love waves and } E W \text { Rayleigh waves } \\
& =\frac{1}{\cos (\mathrm{INV} . \mathrm{AZ})} \text { for } E W \text { Love Waves and } N S \text { Rayleigh waves }
\end{aligned}
$$

\begin{tabular}{|c|c|c|c|c|}
\hline 7.00 & $\begin{array}{c}+\mathrm{Ft}^{3} 310 \\
\mathrm{~F}(1)\end{array}$ & & Tili" & \\
\hline 32 & $3.10000 \mathrm{E}$ & -3 & $3.22581 \mathrm{E}$ & \\
\hline 33 & $\begin{array}{l}000 E \\
000 E\end{array}$ & $\begin{array}{l}-3 \\
-3\end{array}$ & $\begin{array}{l}2500 E \\
3030 E\end{array}$ & 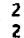 \\
\hline 35 & $\begin{array}{l}3.30000 \mathrm{E} \\
3.40000 \mathrm{E}\end{array}$ & $\begin{array}{l}-3 \\
-3\end{array}$ & $\begin{array}{l}3.03030 \mathrm{E} \\
2.94118 \mathrm{E}\end{array}$ & 2 \\
\hline 36 & $3.50000 E$ & -3 & $2.85714 \mathrm{E}$ & \\
\hline 37 & $3.60000 E$ & -3 & $2.77778 \mathrm{E}$ & \\
\hline 38 & $3.70000 \mathrm{E}$ & -3 & $2.70270 E$ & \\
\hline $\begin{array}{l}39 \\
40\end{array}$ & $\begin{array}{l}3.80000 E \\
3.90000 E\end{array}$ & $\begin{array}{l}-3 \\
-3\end{array}$ & $\begin{array}{l}2.63150 E \\
2.56410 E\end{array}$ & 2 \\
\hline 41 & $4.00000 E$ & -3 & $2.50000 E$ & 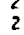 \\
\hline 42 & $4.10000 \varepsilon$ & -3 & $2.43902 \mathrm{E}$ & \\
\hline 43 & $4.20000 \mathrm{E}$ & -3 & $2.38095 \mathrm{E}$ & \\
\hline 64 & $4.30000 E$ & & $2.32558 \mathrm{E}$ & \\
\hline 45 & 4. $40000 E$ & -3 & $2.27273 \mathrm{E}$ & \\
\hline $\begin{array}{l}46 \\
47\end{array}$ & $\begin{array}{l}4.50000 E \\
4.60000 E\end{array}$ & $\begin{array}{l}-3 \\
-3\end{array}$ & $\begin{array}{l}2.22222 \mathrm{E} \\
2.17391 \mathrm{E}\end{array}$ & \\
\hline 48 & $4.70000 E$ & -3 & $2.12760 \mathrm{E}$ & \\
\hline 49 & $4.80000 \mathrm{E}$ & -3 & $2.08333 \mathrm{E}$ & \\
\hline 50 & t.90000E & -3 & $2.04082 E$ & \\
\hline 51 & 5.00000E & -3 & $2.000 \mathrm{GUE}$ & \\
\hline 32 & $5.10000 \mathrm{E}$ & -3 & $1.96078 \mathrm{E}$ & \\
\hline 53 & $20000 E$ & -3 & $1.92308 \mathrm{E}$ & \\
\hline 54 & $5.30000 E$ & -3 & $1.88679 \mathrm{~F}$ & \\
\hline 55 & $5.40000 E$ & -3 & $1.85185 E$ & 2 \\
\hline 56 & $5.50000 E$ & -3 & $1.81818 \mathrm{E}$ & \\
\hline 37 & $5.60000 E$ & -3 & $1.78571 \mathrm{E}$ & 2 \\
\hline $5 \mathrm{~A}$ & $.70000 \mathrm{E}$ & -3 & $1.75439 \mathrm{E}$ & \\
\hline 59 & $5.80000 E$ & -3 & $1.72414 E$ & \\
\hline 60 & $90000 E$ & -3 & $1.69492 \mathrm{E}$ & \\
\hline 61 & $6.00000 E$ & -3 & $1.66667 \mathrm{E}$ & \\
\hline 62 & $10000 \mathrm{E}$ & -3 & $1.63934 \mathrm{E}$ & \\
\hline 63 & $.20000 \mathrm{E}$ & -3 & $1.61290 \mathrm{E}$ & \\
\hline 64 & $6.30000 E$ & -3 & $1.58730 E$ & \\
\hline 05 & $0.43000 \mathrm{E}$ & -3 & $56250 E$ & \\
\hline $\begin{array}{l}66 \\
67\end{array}$ & $\begin{array}{l}6.50000 E \\
6.60000 E\end{array}$ & $\begin{array}{l}-3 \\
-3\end{array}$ & $\begin{array}{l}1.53846 E \\
1.51515 E\end{array}$ & \\
\hline 60 & $6.70000 E$ & -3 & $1.49254 \mathrm{E}$ & \\
\hline 69 & $6.00000 E$ & -3 & $.47059 E$ & \\
\hline 70 & $0.90000 \mathrm{E}$ & -3 & $1.44923 \mathrm{E}$ & \\
\hline 71 & $00000 E$ & -3 & $1.42837 \mathrm{E}$ & \\
\hline 72 & $7.10000 E$ & -3 & $1.40845 \mathrm{E}$ & \\
\hline 73 & 7.20000E & -3 & . $38889 \mathrm{E}$ & $=$ \\
\hline 74 & $7.30000 E$ & -3 & $1.36986 \mathrm{E}$ & 7 \\
\hline $\begin{array}{l}75 \\
70\end{array}$ & $\begin{array}{l}7.42000 \mathrm{E} \\
7.30000 \mathrm{E}\end{array}$ & $\begin{array}{l}-3 \\
-3\end{array}$ & $\begin{array}{r}.35135 \mathrm{E} \\
.33333 \mathrm{~F}\end{array}$ & 2 \\
\hline 77 & T.SJOOOE & -3 & 1.31579t & \\
\hline 78 & $.70000 E$ & -3 & $.29870 \mathrm{f}$ & \\
\hline 79 & $.80000 E$ & -3 & $.28205 \mathrm{~F}$ & \\
\hline AD & $7.93000 E$ & -3 & $26582 \mathrm{E}$ & 2 \\
\hline 11 & 0000 & -3 & $25000 \mathrm{E}$ & \\
\hline
\end{tabular}

The corrected amplitudes are given in units of mm-sec.

\begin{tabular}{|c|c|c|c|}
\hline $\begin{array}{r}\text { CIII } \\
+28 \text { COE }\end{array}$ & 0 & $67019 \mathrm{~F}$ & \\
\hline$E$ & & & \\
\hline & & & \\
\hline & & & \\
\hline & 8 & & \\
\hline & & & \\
\hline & & & \\
\hline & & & \\
\hline & & & \\
\hline & & & \\
\hline & & & \\
\hline & & & \\
\hline 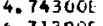 & & $4 E$ & - \\
\hline & & & \\
\hline .68 & & $75 t$ & 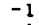 \\
\hline 01 & & & \\
\hline 01 & & $4 E$ & \\
\hline & & & \\
\hline 56 & & $4 E$ & \\
\hline 34 & & & \\
\hline $5 ?$ & & & \\
\hline .50 & 0 & $8 E$ & \\
\hline 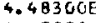 & & & \\
\hline 4.45 & & & \\
\hline .43 & & & \\
\hline 4. & & & \\
\hline$=4$ & & IE & \\
\hline E & & & \\
\hline - 3 & $i$ & & \\
\hline & 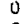 & & \\
\hline 4.3 & 0 & & \\
\hline 4.3 & 0 & & \\
\hline $31>>$ & 0 & & \\
\hline - 3 & & & \\
\hline $28-2>$ & 0 & & \\
\hline & 0 & & \\
\hline & & & \\
\hline 4. 2 & 0 & he & \\
\hline & & & \\
\hline IE & 0 & $3 F$ & \\
\hline 24 & 0 & & \\
\hline & $c$ & $2 \mathrm{~F}$ & \\
\hline & & & \\
\hline & 0 & $2.21311 \mathrm{E}$ & \\
\hline & & & \\
\hline & 0 & & \\
\hline $9.7<4.24$ & 6 & $2.0313 B t$ & \\
\hline
\end{tabular}

\begin{tabular}{|c|c|c|c|}
\hline & & & \\
\hline $1.01557 \mathrm{~F}$ & & $96 \mathrm{~F}$ & \\
\hline $87 F$ & & $954 \mathrm{~F}$ & \\
\hline $059 \mathrm{E}$ & C & $20 \mathrm{E}$ & \\
\hline $942 F$ & 0 & $22 \mathrm{E}$ & \\
\hline $30 E$ & & & \\
\hline $462 \mathrm{E}$ & e & $0.5762 \mathrm{E}$ & \\
\hline $26005 E$ & & $.02009 E$ & \\
\hline $49 \mathrm{~F}$ & 0 & $5 E$ & \\
\hline $18600 \mathrm{E}$ & & $5.945 \times 1 F$ & \\
\hline $4 F$ & & 5.9 & \\
\hline $9 E$ & & & \\
\hline $3 E$ & & 5.93 & \\
\hline $1.6^{\circ}$ & & 5.79 & \\
\hline $03 E$ & & 5.76 & \\
\hline $5 E$ & 0 & 5.72 & \\
\hline & & 5.6 & \\
\hline & 0 & 5.65 & \\
\hline $8 \mathrm{E}$ & 0 & & \\
\hline & & 5.5 & \\
\hline & 0 & 5.5 & \\
\hline $6 \mathrm{~F}$ & & 5 & \\
\hline CE & 0 & & \\
\hline E & c & 5.44 & \\
\hline & & 5.41 & \\
\hline & $\mathrm{g}$ & 5.3 & \\
\hline 5 & & 5.34 & \\
\hline & a & 5.31 & \\
\hline & 0 & 5.2 & \\
\hline & 0 & & \\
\hline & & $a r$ & \\
\hline & 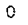 & & \\
\hline & 0 & 5.1 & \\
\hline $4 E$ & 0 & 5.11 & \\
\hline 3.1 & 0 & 5.0 & \\
\hline $15 \mathrm{~F}$ & 0 & 5.0 & \\
\hline & 0 & & \\
\hline $5118 \%$ & 0 & 4.98 & \\
\hline & 0 & & \\
\hline $10 \geq F$ & 0 & 4.92 & \\
\hline & 0 & & \\
\hline $3.42417 \mathrm{E}$ & 0 & & \\
\hline & c & $53 \mathrm{E}$ & \\
\hline & 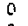 & & \\
\hline$F$ & 0 & $4.77677 \mathrm{r}$ & \\
\hline & $i$ & & \\
\hline & 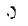 & & \\
\hline 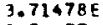 & $a$ & 4.688705 & \\
\hline & 3 & & \\
\hline & & 220 & \\
\hline & & & \\
\hline
\end{tabular}

\begin{tabular}{|c|c|c|}
\hline FINITIII & & PHASFIII \\
\hline 4 & 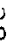 & $\begin{array}{l}-1.61367 F \\
-1.630845\end{array}$ \\
\hline 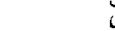 & 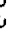 & -1.699036 \\
\hline$i$ & u & $-1.72730 \mathrm{E}$ \\
\hline & 0 & $-1.67512 \mathrm{E}$ \\
\hline 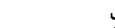 & 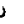 & $-1.67489 E$ \\
\hline c & 0 & $-1.67837 F$ \\
\hline & i & -1.6263 AF \\
\hline c & u & -2.635435 \\
\hline & 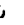 & $-1.679 \mathrm{n} 1 \mathrm{~F}$ \\
\hline & 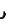 & $-1.04 \cos F$ \\
\hline se & 0 & $-1.60258 E$ \\
\hline c & 0 & -1.61 CBAF \\
\hline & 0 & $-1.6098 B E$ \\
\hline & 0 & $-1.63644 F$ \\
\hline & is & $-1.62997 \mathrm{~F}$ \\
\hline c & $u$ & $-1.61500 \mathrm{E}$ \\
\hline & i & $-1.56757 \mathrm{E}$ \\
\hline : & 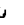 & $-1.6 ? 797 f$ \\
\hline 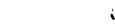 & v & -1.651035 \\
\hline 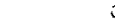 & v & $-1.6>556 \mathrm{~F}$ \\
\hline & u & $-1.64463 F$ \\
\hline is & u & $-1.6 \times 243 F$ \\
\hline : & 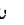 & -1.674308 \\
\hline & 0 & $-1.55292 \mathrm{~F}$ \\
\hline & $\mathrm{c}$ & $-1.62 \mathrm{Cn} 3 \mathrm{~F}$ \\
\hline & ن ن & $-1.63741 \mathrm{~F}$ \\
\hline & ن & $-1.64413 \mathrm{~F}$ \\
\hline & i & $-2.69234 E$ \\
\hline & u & -1.732446 \\
\hline & 0 & $-1.66547 \mathrm{~F}$ \\
\hline & 0 & $-1.58645 t$ \\
\hline & 0 & $-1.61076 \mathrm{E}$ \\
\hline & c & $-1.62006 \mathrm{~F}$ \\
\hline & 0 & -1.590316 \\
\hline & 0 & $-1.56051 E$ \\
\hline & 0 & $-1.56138 \mathrm{~F}$ \\
\hline & u & $-1.55772 E$ \\
\hline & $u$ & $-1.56173 E$ \\
\hline & 0 & $-1.56257 E$ \\
\hline & 0 & $-1.60961 \mathrm{E}$ \\
\hline c & 0 & $-1.6960 \mathrm{AF}$ \\
\hline & 0 & $-1.69592 E$ \\
\hline c & 0 & $-1.7351 \mathrm{AF}$ \\
\hline 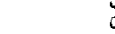 & 0 & $\begin{array}{l}-1.228807 \\
-1.92297 \mathrm{E}\end{array}$ \\
\hline s & 6 & $-2.01683 \mathrm{~F}$ \\
\hline 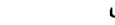 & u & $-2.10976 \mathrm{E}$ \\
\hline c & 6 & $-2.1576 A F$ \\
\hline & $i$ & $-2.28>23 F$ \\
\hline
\end{tabular}

FIG. 6. A computer output for phase equalization of surface wave signals from a network of WWNSS. The particular result shown here is for a Rayleigh wave $R_{2}$ recorded at Stuttgart, Germany, from the Kurile Islands aftershock of October 20, 1.963.

An example of a phase equalization is given in Figure 6 . The wave $R_{2}$ had traveled a distance of $31024.0 \mathrm{~km}$. along the major are from the Kurile Is. to Stuttgart. The time difference between the origin-time and the onset of the filtered time series was 7965.0 sec. The appropriate phase velocities (in $\mathrm{km} / \mathrm{sec}$ ) for that path are listed in column four. The spatial initial phase of the far-field vertical component of $R_{2}$ is generally given by

$\operatorname{PHASE}(I)=A(I)-\operatorname{FRP}(I)-\operatorname{PHINS}(I)+|\mathrm{FIN}(I)|+|\mathrm{STEP}|-\operatorname{POLAR}$ 
In our present example

$$
\begin{aligned}
A & =N+f\left(\frac{31024}{C}-7965\right) \quad N=7 \\
f & =\text { Frequency in cycles/sec } \\
C & =\text { phase velocity in } \frac{\mathrm{km}}{\mathrm{sec}}
\end{aligned}
$$

FRP $=$ The Fourier-analysis phase (in circle units)

PHINS $=$ The instrumental phase advance (in circle units $)+$ instrumental polarity correction.

STEP $=-\frac{1}{4}$ (The spectral phase of the Heaviside unit step, in circle units)

POLAR $=\frac{1}{4}$ (polar phase shift)

FIN $=$ phase retardation due to horizontal extent of the seismic source (BenMenahem, 1961)

The instrumental phase advance for the WWNSS system is given by

$$
\left.\frac{1}{\pi}\left[\tan ^{-1}\left(\frac{\omega_{0}}{\omega}\right)+\tan ^{-1}\left(\frac{\omega_{g}}{\omega}\right)\right]-\frac{1}{4} \text { (in circle units }\right) \cdot
$$
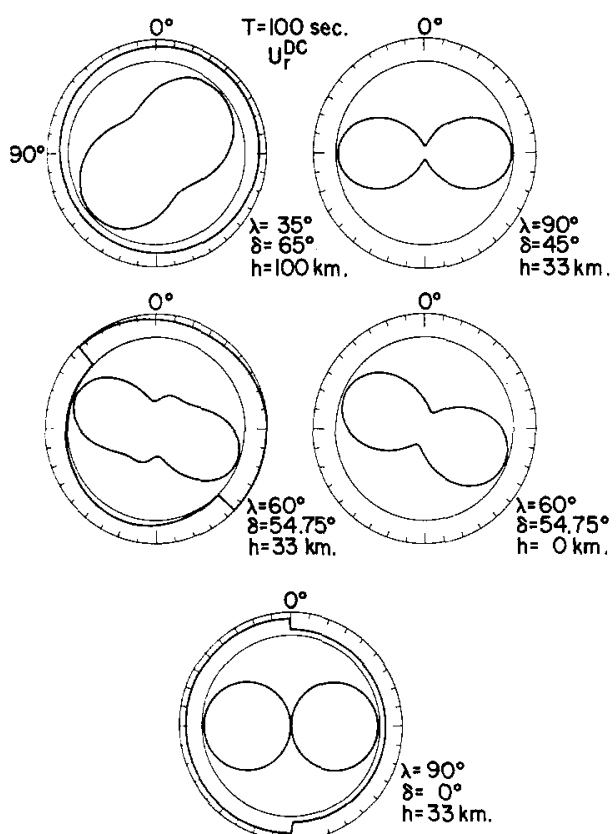

FUNDAMENTAL RAYLEIGH MODE OCEANIC MODEL
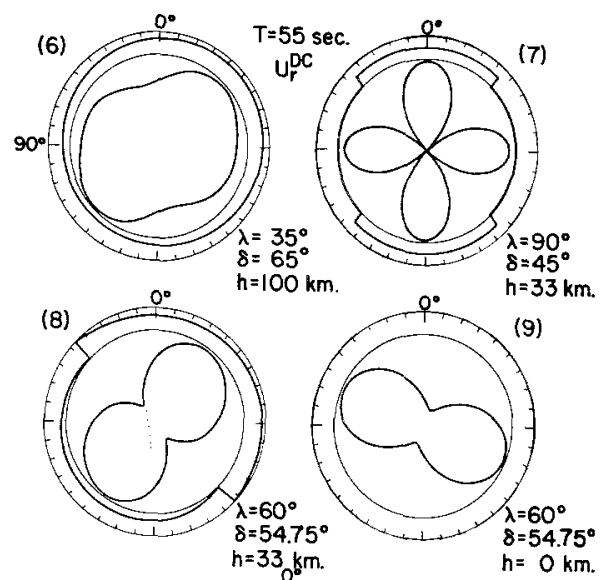

(10)

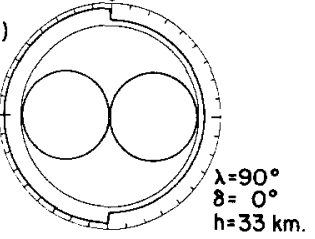

FUNDAMENTAL RAYLEIGH MODE, OCEANIC MODEL

Frg. 7

Figs. 7, 7a, 7b. Calculated radiation patterns of Rayleigh waves $\left(U_{r}\right)$ for various values of the period $(T)$, source depth $(h)$ and source orientation $(\delta, \lambda)$. The source is that of a displacement dislocation (DC) in a multilayered oceanic half-space, and strikes to the north $\left(0^{\circ}\right)$. Spatial initial phase is drawn in a unit ring. 

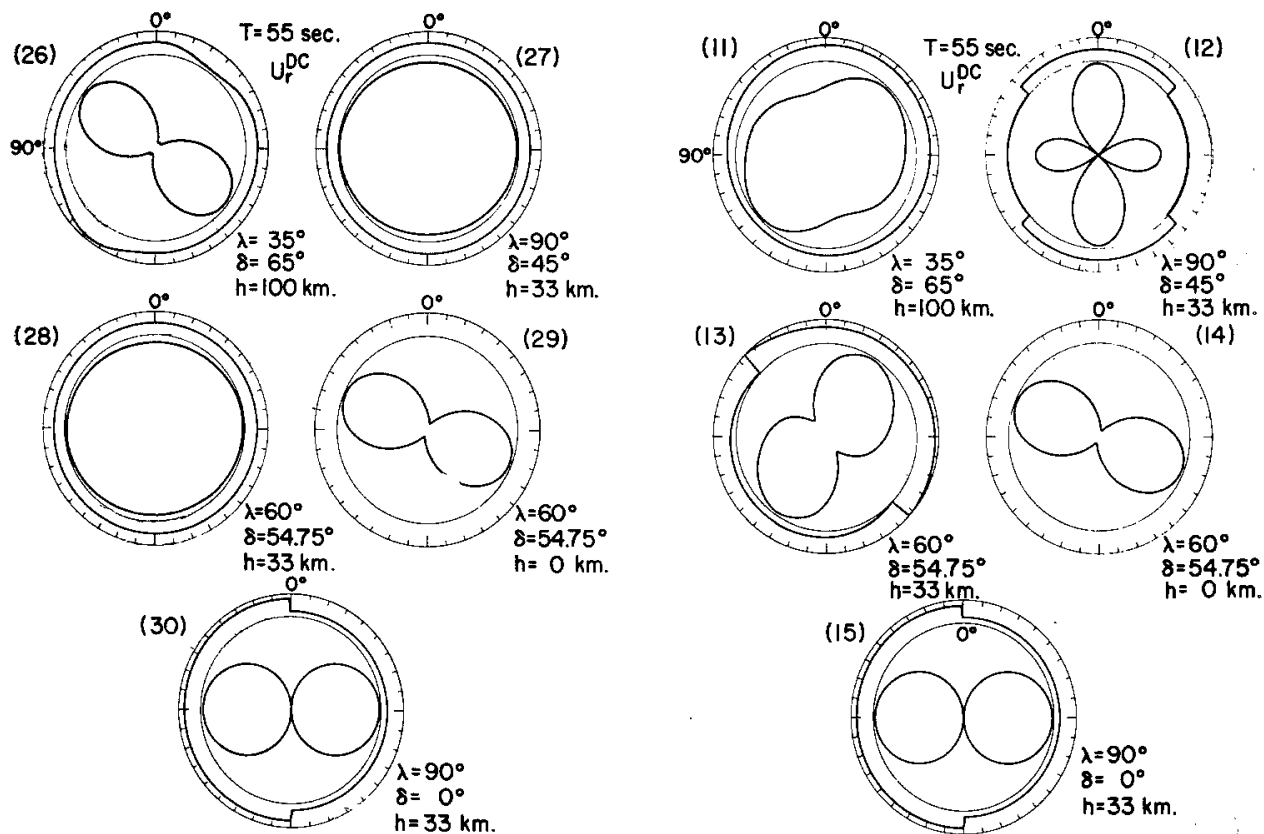

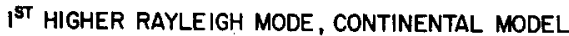

FUNDAMENTAL RAYLEIGH MODE, CONTINENTAL MODEL

Fig. 7a
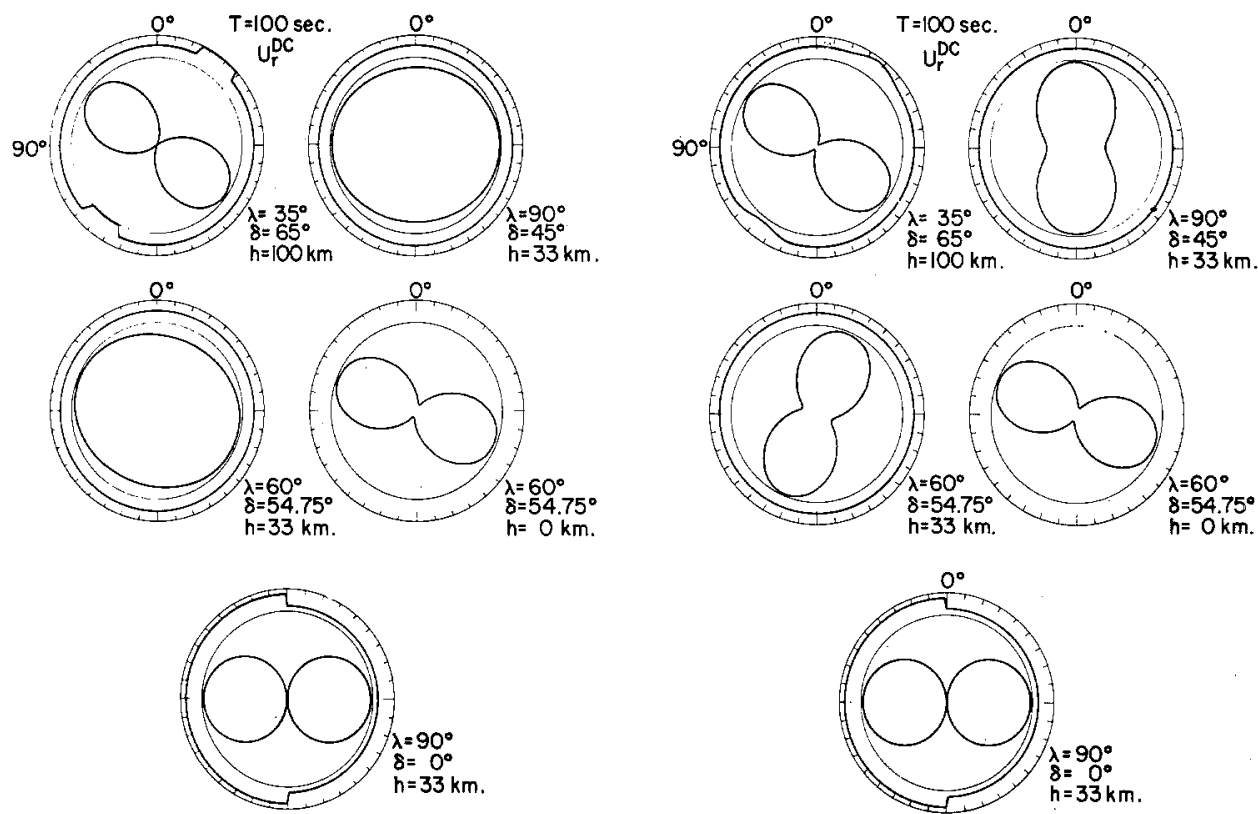

IST HIGHER RAYLEIGH MODE CONTINENTAL MODEL

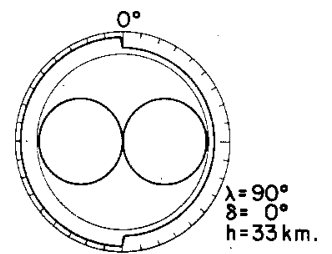

IST HIGHER RAYLEIGH MODE SHIELD MODEL

Fig. $7 \mathrm{~b}$

The finiteness phase was found to be negligible in our present example. The instrumental polarity correction is always zero for Rayleigh waves recorded on the Press-Ewing system. For Love waves it is either $\pi$ or zero, depending on the inverse azimuth.

Some typical radiation patterns for Rayleigh waves are shown in Figures, 7, 7a, 7b. 
Their dependence on depth, frequency, mode, source orientation and the Earth's structure has been explicitly formulated and calculated by Ben-Menahem and Harkrider (1964) and Harkrider (1967) for various flat earth models. The numerical calculation scheme is based on the Haskell-Harkrider formalism (Haskell, 1963; Harkrider, 1964). The basic expressions from which the far-field spectral patterns are calculated can be conveniently written in the dimensionless form

$$
\begin{aligned}
& \frac{U_{\theta}(\omega)}{U_{0}(\omega)}=\left[\frac{d S}{4 \pi a^{2}}\right] \frac{e^{-\gamma \Delta-\frac{3 \pi i}{4}}}{\sqrt{\sin \Delta}}\left[\left(K_{L} a\right)^{3 / 2} \sqrt{ } 8 \pi\right]\left[\frac{\mu_{\varepsilon} A_{L}}{K_{L}}\right] \\
& \cdot\left[\begin{array}{l}
\dot{v}_{s} \\
\dot{v}_{0}
\end{array}\right]\left[p_{L}+i q_{L}\left(\frac{\tau_{L_{s}}^{*}(h)}{\mu_{s}}\right)\left(\frac{C_{L}}{\dot{v}_{s}(h)}\right)\right] \\
& p_{L}=\left(\frac{1}{2} \sin \lambda \sin 2 \delta\right) \sin 2 \theta+(\cos \lambda \sin \delta) \cos 2 \theta \\
& q_{L}=-(\cos \lambda \cos \delta) \sin \theta+(\sin \lambda \cos 2 \delta) \cos \theta \\
& \frac{U_{r}(\omega)}{U_{0}(\omega)}=\left[\frac{d S}{4 \pi a^{2}}\right] \frac{e^{-\gamma \Delta-\frac{3 \pi i}{4}}}{\sqrt{\sin \Delta}}\left[\left(K_{R} a\right)^{3 / 2} \sqrt{8 \pi}\right]\left[\frac{\mu_{s} A_{R}}{K_{R}}\right] \\
& \text { - }\left[\frac{\dot{u}_{0}^{*}}{\dot{w}_{0}}\right]\left[\frac{\dot{u}_{s}^{*}}{\dot{w}_{0}}\right]\left[s_{R}\left\{1+\frac{\sigma_{R_{s}}^{*}(h)}{\mu_{s}} \frac{C_{R}}{\dot{u}_{s}^{*}} \frac{1-2 \sigma_{s}}{1+\sigma_{s}}\right\}\right. \\
& \left.-i q_{R}\left(\frac{\tau_{R_{s}}(h)}{\mu_{s}}\right)\left(\frac{C_{R}}{\dot{u}_{s}^{*}}\right)+p_{R}\right] \\
& \frac{U_{z}(\omega)}{U_{0}(\omega)}=\left[\frac{U_{T}(\omega)}{U_{0}(\omega)}\right]\left[\frac{\dot{w}_{0}}{\dot{u}_{0}{ }^{*}}\right] e^{\frac{\pi i}{2}} \\
& s_{R}=\frac{1}{2} \frac{1+\sigma_{s}}{1-\sigma_{s}} \sin \lambda \sin 2 \delta \\
& q_{R}=(\sin \lambda \cos 2 \delta) \sin \theta+(\cos \lambda \cos \delta) \cos \theta \\
& p_{R}=(\cos \lambda \sin \delta) \sin 2 \theta-\left(\frac{1}{2} \sin \lambda \sin 2 \delta\right) \cos 2 \theta \text {. }
\end{aligned}
$$

Notation is the same as in Ben-Menahem and Harkrider (1964). The angles $\lambda$ and $\delta$ are the slip and dip angles at the source $0^{\circ} \leqq \delta \leqq 90^{\circ}, 0^{\circ} \leqq \lambda \leqq 360^{\circ}$.

The displacement vector at the observing station $U=\left(u_{r}, u_{\theta}, u_{z}\right)$ has been normalized to $U_{0}(\omega)$ the spectral displacement at the source

$$
U_{0}(\omega)=\left|U_{0}(\omega)\right|\left(\cos \lambda e_{\theta_{0}}+\sin \lambda \cos \delta \boldsymbol{e}_{\varphi_{0}}+\sin \lambda \sin \delta \boldsymbol{e}_{r_{0}}\right)
$$

with

$$
U_{0}(\omega)=\left|U_{0}(\omega)\right|=U_{0} \int_{0}^{\infty} f(t) e^{-i \omega t} d t
$$


$U_{0}$ being the amount of displacement jump at the dislocation. $\left(\boldsymbol{e}_{\theta_{0}}, \boldsymbol{e}_{\varphi_{0}}, \boldsymbol{e}_{r_{0}}\right)$ is a vector base at the source. (Figure 7c).

For a unit-step time dependence $f(t)=H(t), U_{0}(\omega)=U_{0} / i \omega$. The term responsible for the geometric spread over the half-space, namely $(2 \pi r)^{-1 / 2}$, has been replaced by the corresponding term for wave propagation over a sphere, that is $(2 \pi a \sin \Delta)^{-1 / 2}$, where $a$ is the radius of the Earth. The role of the area element $d S$ appearing in equations (2) to (5) has been indicated by Ben-Menahem and Singh (1967). It is assumed that the displacement components appearing in equations (2), (4) and (5) have already been corrected for the phase and amplitude distortion of the recording instrument, for the polar phase shift and for the source's finiteness.

It follows at once from equations (2) to (6) that certain relations exist which may introduce non-uniqueness into the inversion of radiation-pattern data. Using the notation $U\left(\delta^{\circ}, \lambda^{\circ}, \theta^{\circ}\right)$ to indicate the dependence of the patterns on the azimuth angle

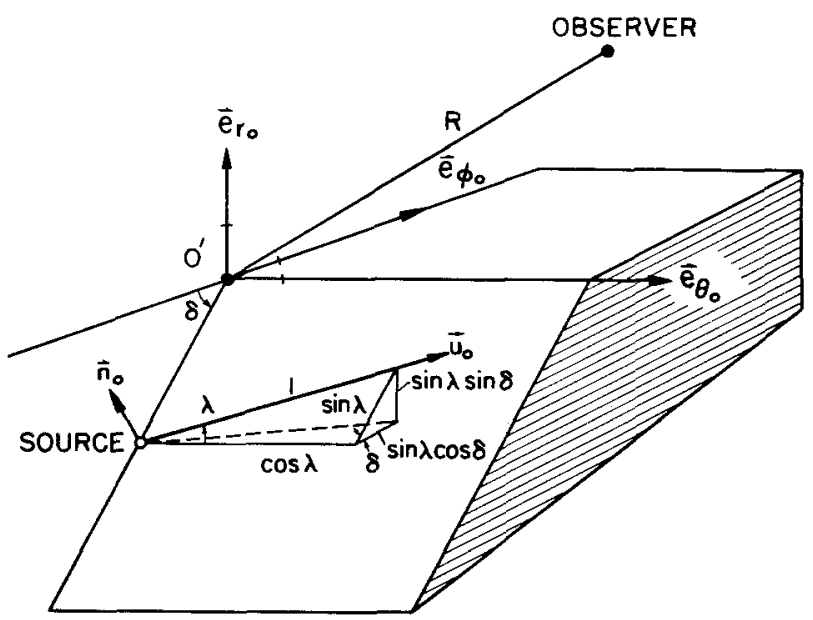

Fig. 7c. Geometry of a shear dislocation source.

and the orientation parameters, we find

$$
\begin{aligned}
U_{r}(45,0 ; \theta) & \equiv U_{r}(90,-45 ; 90-\theta) \\
U_{r}(0,0 ; \theta) & \equiv-U_{r}(90,90 ; 90+\theta) \\
U_{\theta}(45,0 ; \theta) & \equiv U_{\theta}(90,135 ; 90-\theta) \\
U_{\theta}(90,0 ; \theta) & \equiv-2 U_{\theta}(45,90 ; \theta-45) .
\end{aligned}
$$

The asymmetry of the radiation field is diagnostic of the source's dimensions. It is therefore useful to perform a routine finiteness-test. Guessing an initial value for the fault's strike on the basis of the extent of the aftershock area, we may search for a best fit of the observed directivity to a set of theoretical curves and thus come up with an estimate for the fault's length and the speed of rupture. Figure 8 shows the spectral ratio of $R_{1}$ and $R_{2}$ (including a correction for the excessive attenuation of $R_{2}$ ) 
at the AAE station. We may conclude from it that the extent of the rupture at the aftershock's origin did not exceed $75 \mathrm{~km}$.

In order to turn the radiation pattern programs into a useful tool, we have devised a search routine which takes in a set of measured equalized amplitudes (at a chosen frequency) and fits to it a "best" pattern by minimizing the sum

with respect to

$$
\sum_{\text {stations }}\left[\frac{A_{\text {obs }}}{\left(A_{\text {obs }}\right) \max }-\frac{A_{\text {cal }}}{\left(A_{\text {cal }}\right) \max }\right]^{2}
$$

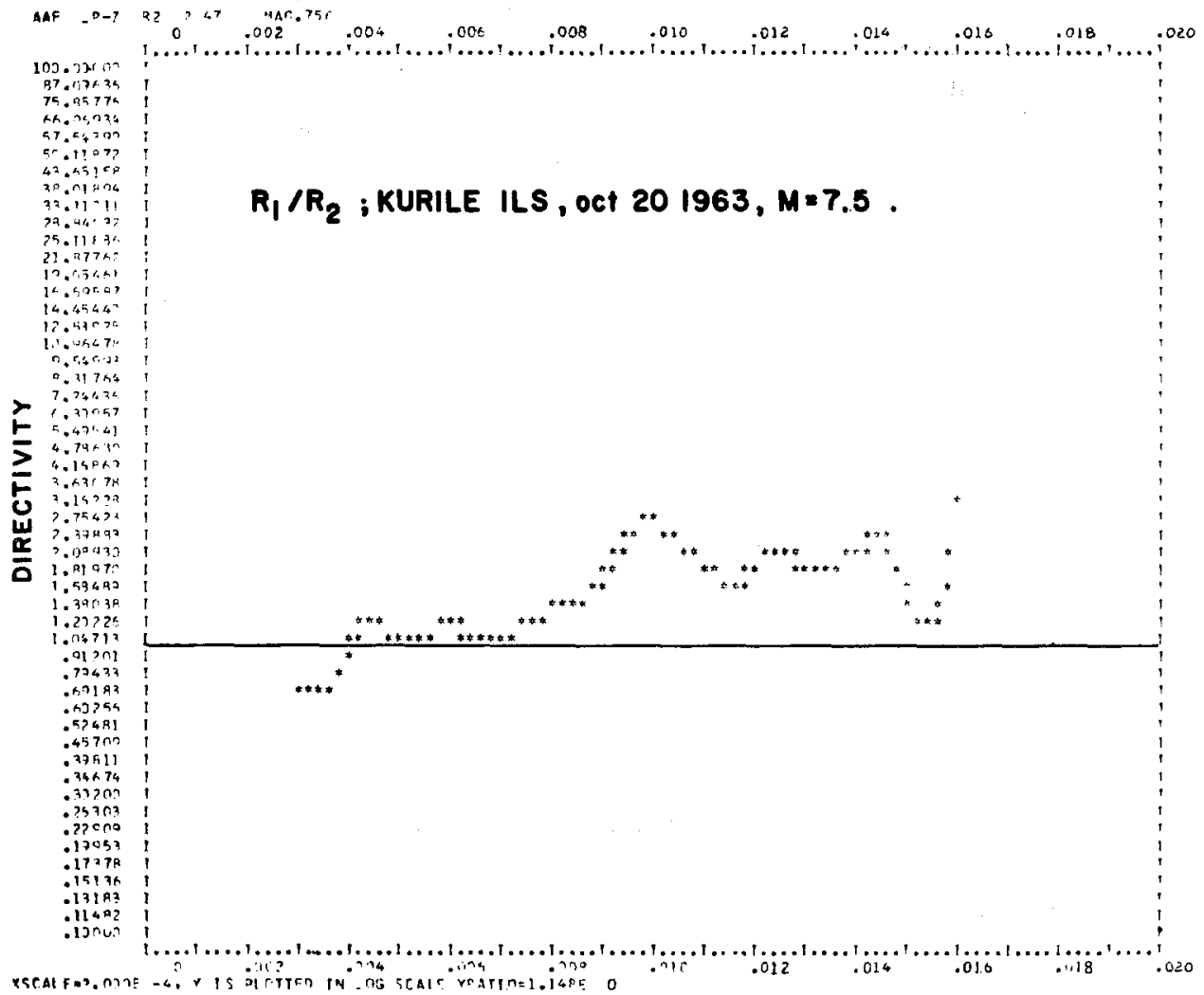

FIG. 8. A computer output for a routine calculation of the directivity function. The example shows the spectral ratio of equalized Rayleigh waves $R_{1}$ and $R_{2}$ recorded at the WWNSS AAE.

a grid of angles $\delta: 0\left(5^{\circ}\right) 90^{\circ} ; \lambda: 0\left(5^{\circ}\right) 180^{\circ}$. Having found $\delta_{\min }$ and $\lambda_{\min }$ a finer grid is taken as $\left(\delta_{\min }-5^{\circ}\right)\left(1^{\circ}\right)\left(\delta_{\min }+5^{\circ}\right)$ and $\left(\lambda_{\min }-5^{\circ}\right)\left(1^{\circ}\right)\left(\lambda_{\min }+5^{\circ}\right)$. The final choice is plotted and compared with the observations. Figures 9, 10 and 10a exhibit the results for such a case. Note that the solution obtained from the input data for $T=200 \mathrm{sec}$ differs from the solution obtained for $T=166 \mathrm{sec}$. An inspection of equation (4) for this case shows that it is indeed a non-uniqueness which in most cases is resolvable by using additional Love wave data. Although the bias is somewhat toward the solution $\delta=80^{\circ}, \lambda=90^{\circ}$ (Figure 10b), the evidence for this particular case is by no means conclusive.

The final stage of the analysis is reached through the reconstruction of the source's time function from the initial phases and the initial amplitudes. If the corrected amplitude spectrum at each station is further compensated for its azimuthal depend- 

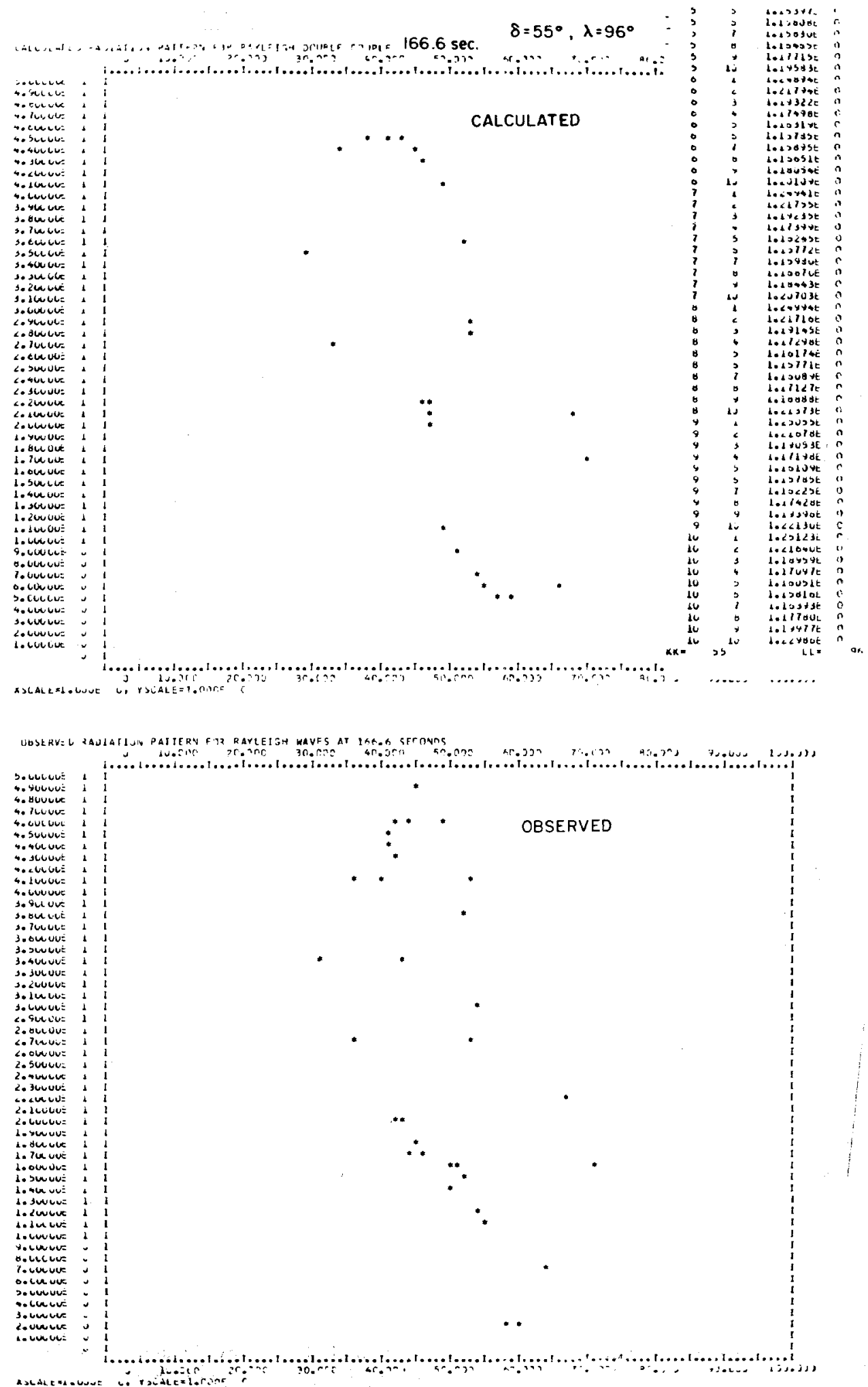

FIG. 9. Calculated versus observed patterns for a period of $166.6 \mathrm{sec}$ The search yielded: $\delta=55^{\circ}, \lambda=96^{\circ}$. 

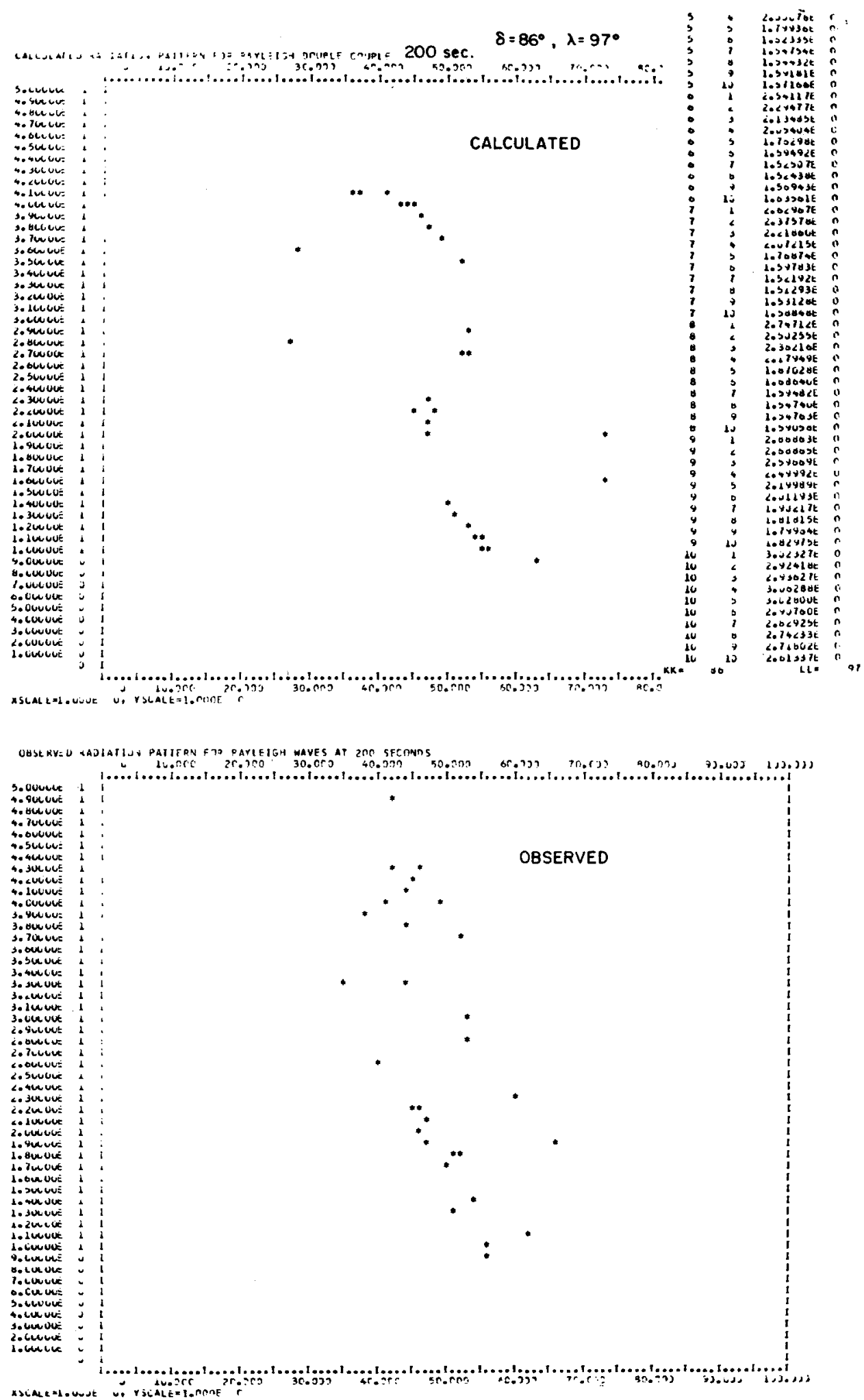

FIG. 10. A computer output with results of search for best fit of observed and calculated radiation patterns of Rayleigh waves at a given period $(200 \mathrm{sec})$. Horizontal and vertical scales are not equal. The last stage of the search with the final result $\left(\delta=86^{\circ}, \lambda=97^{\circ}\right)$ is shown in the right of the upper sheet. 
ence, then whatever remains must be proportional to the spectrum of the time function at the source. An example is shown in Figures 11 and 11a. Here we have normalized the average residuals of all stations by the value of this average at $f_{0}=6 \mathrm{mc} / \mathrm{sec}$ and compared it with the normalized spectrum of a unit step function. Because of the non-uniqueness of the spatial orientation at the source we have repeated this procedure for the two fault plane solutions obtained earlier through the inversion of the Rayleigh radiation patterns (Figures 9,10 ).
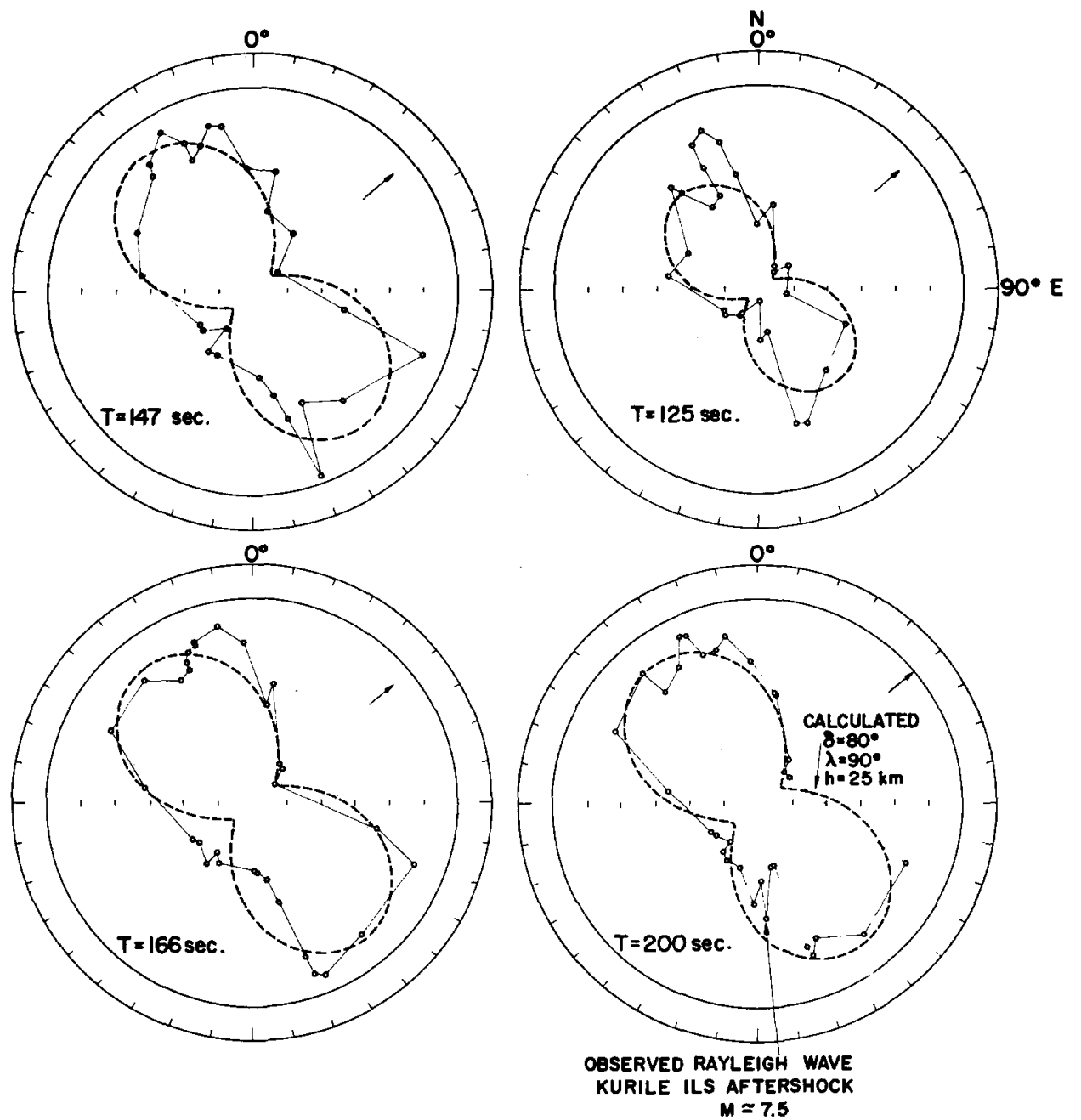

FIG. 10a. Rayleigh wave patterns for various periods.

It should be mentioned that the finiteness, however small, always enhances the relative decay of the higher frequencies. A one-dimensional extent introduces the factor [sin $X / X]$ (Ben-Menahem, 1961). The azimuthal average of this factor behaves like $1 / \omega$. Likewise, a two-dimensional extent, which is physically feasible, will introduce the factor $1 / \omega^{2}$ into the time function. Section (B) in Figures 11 and 11a includes a one-dimensional spectral finiteness correction.

Initial motions and initial phases are also useful in yielding additional clues. Thus, initial phases of Rayleigh waves $\left(U_{z}\right)$ support the solution $\lambda=90^{\circ}, \delta=45^{\circ}, h=25 \mathrm{~km}$. 
(Figure 12). The predicted theoretical value for the source is $3 \pi / 4$, independent of the azimuth. On the other hand initial motions of $P$ waves support the alternative solution $\lambda=90^{\circ}, \delta=80^{\circ}$.

\section{Analysis of Body Waves}

While processing a great number of records obtained from the USCGS network of WWNSS the need arose for means of rapid identification of the phases on the records.

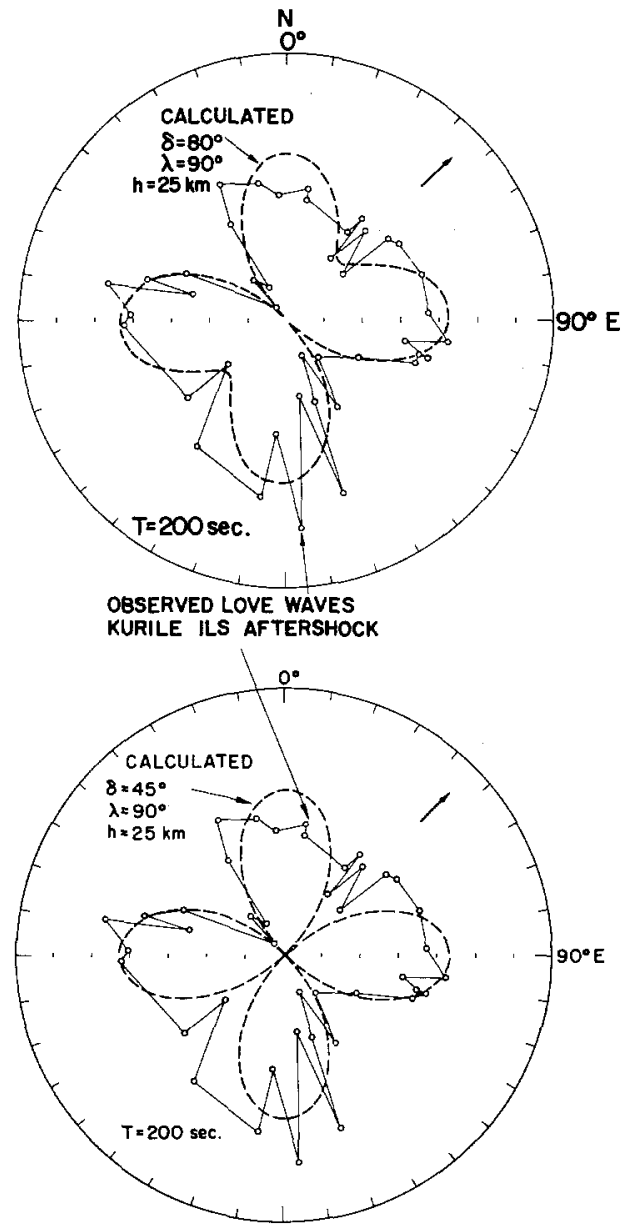

Frg. 10b. Love wave radiation patterns for two source models.

The ordinary procedure is to take the existing estimate of the epicenter, the depth and the time of origin of the event, compute the distance to a station, and then, using travel-time tables or charts, obtain the travel times of the various phases. These times had to be added to the estimated time of origin so that the expected arrival times could. be obtained. At certain distances and depth ranges some phases are unobservable.

To use our computer program we have to supply it with the estimated position of the epicenter, the depth and the time of origin. Some alpha-numeric description of the event is added for identification purposes. The program computes the expected arrival times at every. WWNSS and some other selected stations of any number of phases 


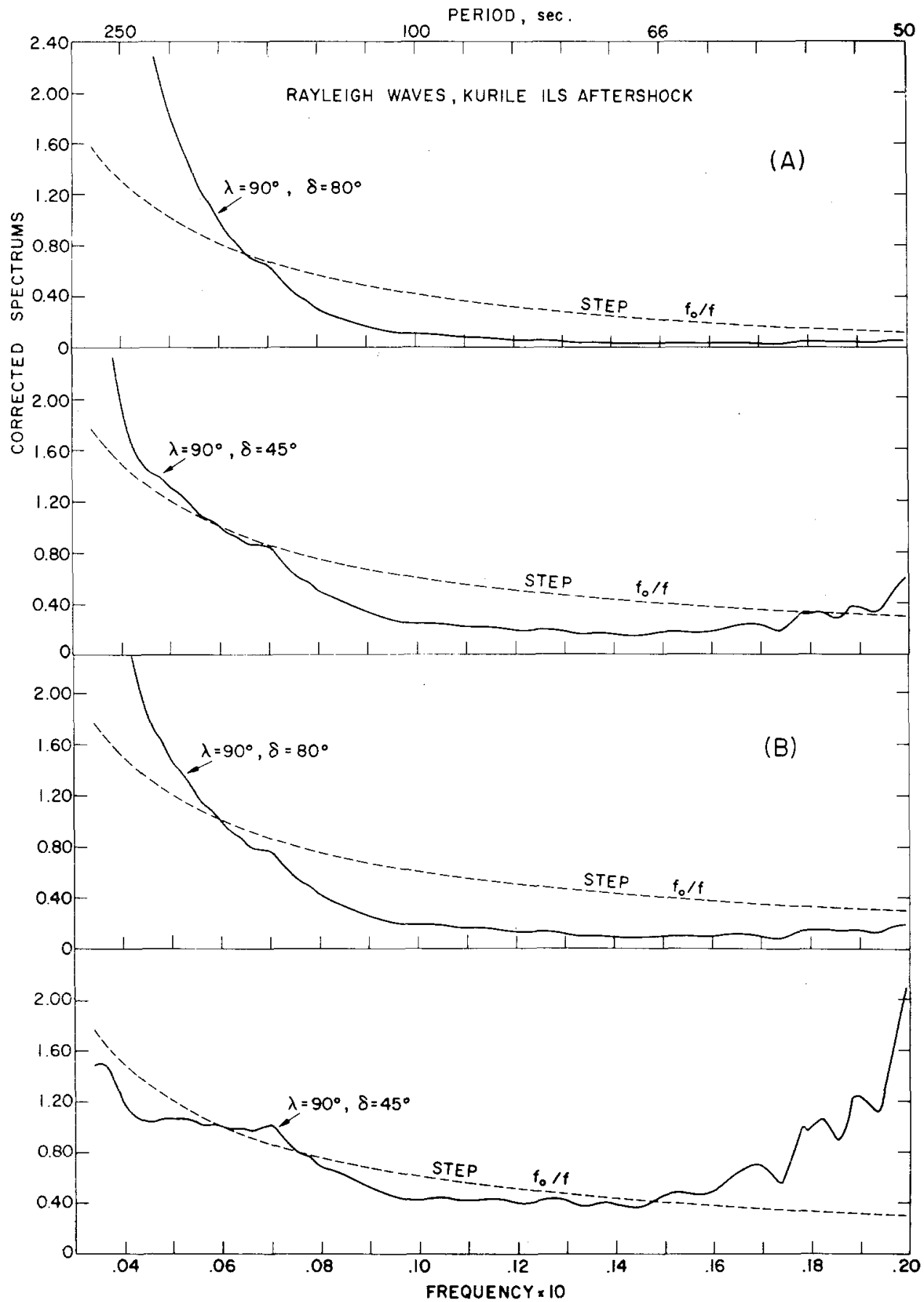

FIG. 11

FIGS. 11-11a. (A) The observed amplitude spectrum $U_{0}(\omega) / U_{0}\left(\omega_{0}\right)$ of the normalized sourcetime function. It was obtained from amplitude equalization of mantle surface waves that originated at the source of the shock of October 20,1963 . (B) The amplitude spectrum (A) multiplied by the spectral function $f / f_{0}$ to account for one-dimensional finiteness.

we choose to include. For each station the program will print up to ten arrival times per line, and in case more than ten phases are of interest, the additional times are printed on further sheets of output. Unobservable phases are pointed out by printing asterisks $\left(^{*}\right)$ instead of the arrival times. 


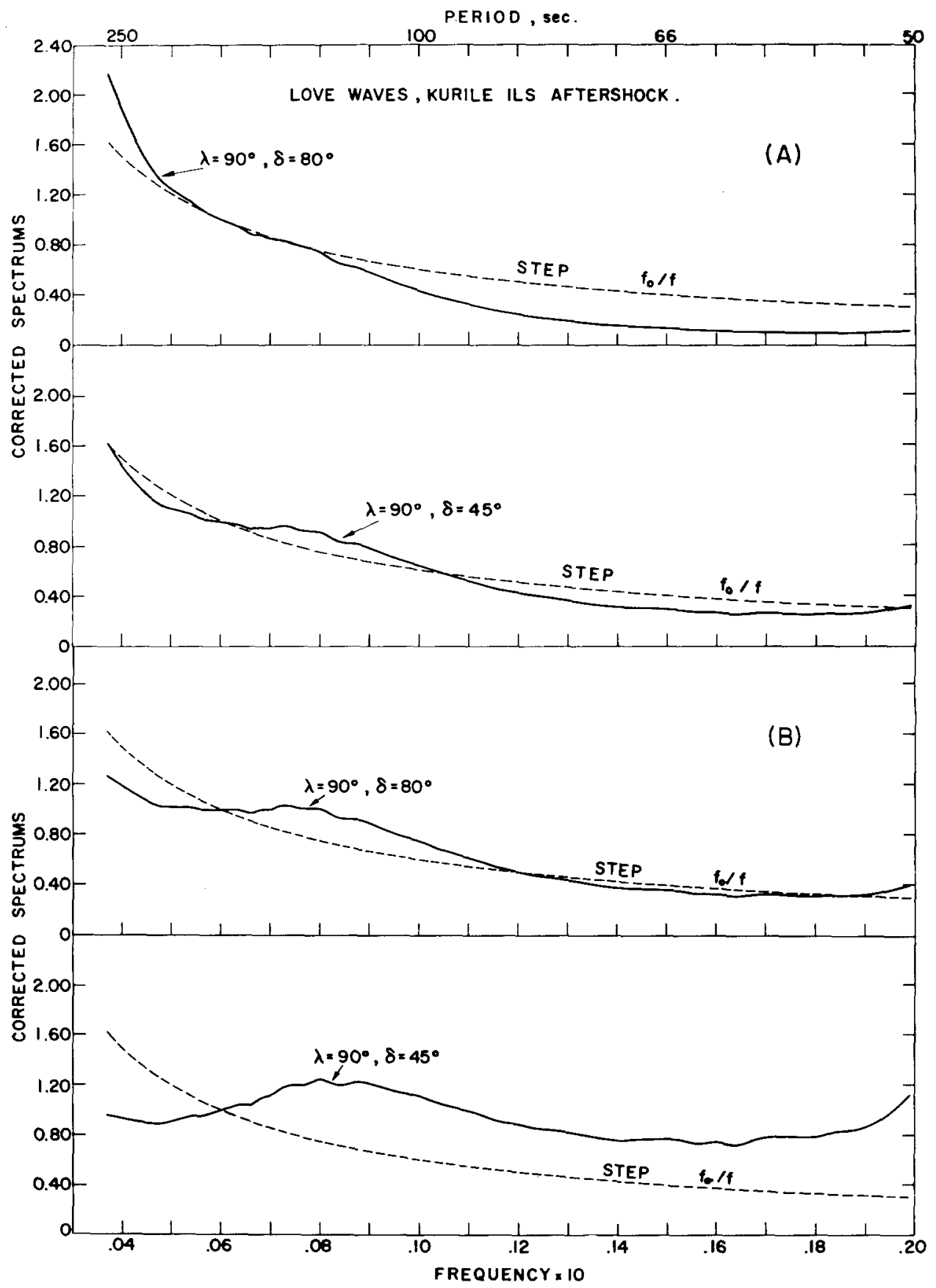

FIG. 11a

The program itself holds the coordinates of all the stations in question, and also the various travel-time tables at intervals of one degree for 14 values of depth, from "Surface" to $h=.12 R$, a method which is identical to the one used for the times of $P$ and $S$ in the Jeffreys-Bullen Seismological Tables (1958).

The tables used are all based essentially on the $J-B$ Tables, but for interpolation, 
values have also been taken from times computed by Jeffreys and Shimshoni (1964), Travis (1965) and Shimshoni (1966), with some minor corrections where the need for them arose.

The computation of the distance between station and epicenter is by standard methods, using geocentric latitudes. For each phase the tables were consulted for the two nearest values of depth, and for each of them the two nearest entries to the desired distance were taken. If for example the depth was 190 kilometers, and the distance $63.78^{\circ}$, the entries $(63.02),(63.03),(64.02)$ and $(64.03)$ in the $(\Delta, h)$ tables were

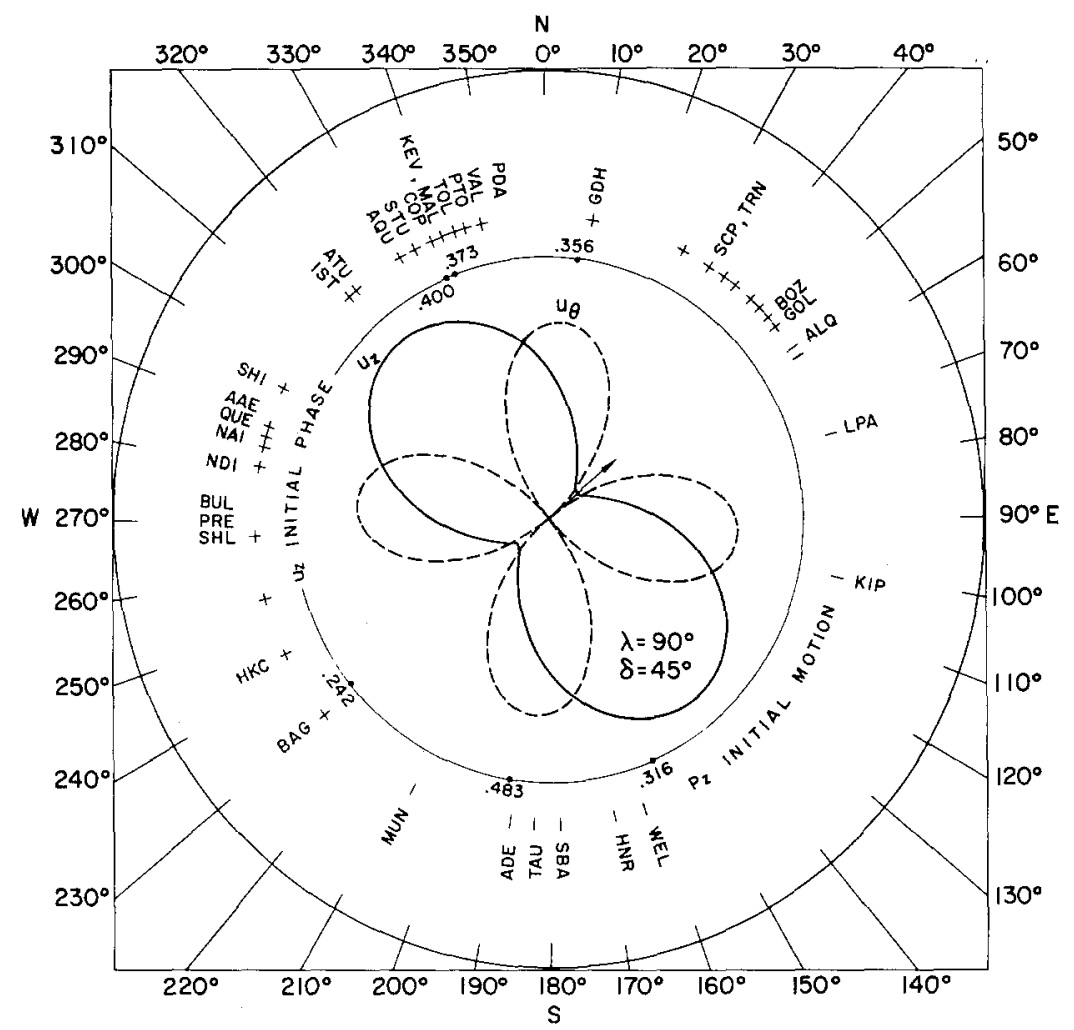

FIG. 12. The force-system at the source as obtained via initial phases and radiation patterns of both Love and Rayleigh waves.

looked up. The four points thus obtained form the corners of a rectangle in the $\Delta-h$ plane, with the desired depth and distance being somewhere inside the rectangle. The actual time was then obtained by three processes of linear interpolation.

If even one of the four corners of the rectangle was for an unobservable $\Delta-h$ combination, a rejection of this phase results. The travel times thus obtained were added to the estimated time of origin, giving the expected arrival times.

Till now we included in our program the following 16 phases:

$$
\begin{aligned}
& P, \quad p P, P c P, \quad P K P, \quad P P, \quad P c S, \quad P S, \quad P P P \\
& S, \quad s S, \quad S S, \quad S S S, \quad S K S, \quad S c S, \quad S c P, \quad S P
\end{aligned}
$$


The accuracy of our interpolation process is within one second, an accuracy which is in line with that of the $J-B$ times. Figure 13 shows a printed sample of the output of this program.

More than 1000 shocks, some originating as far back as 1911, have been processed to date by the method of first motion and the method of the polarization angle. This effort, which is due to the Ottawa Dominion Observatory, the $S$-wave Project group at St. Louis University and many other individuals, rendered some interesting results. While these methods themselves are elegant and simple to use, the interpretation of

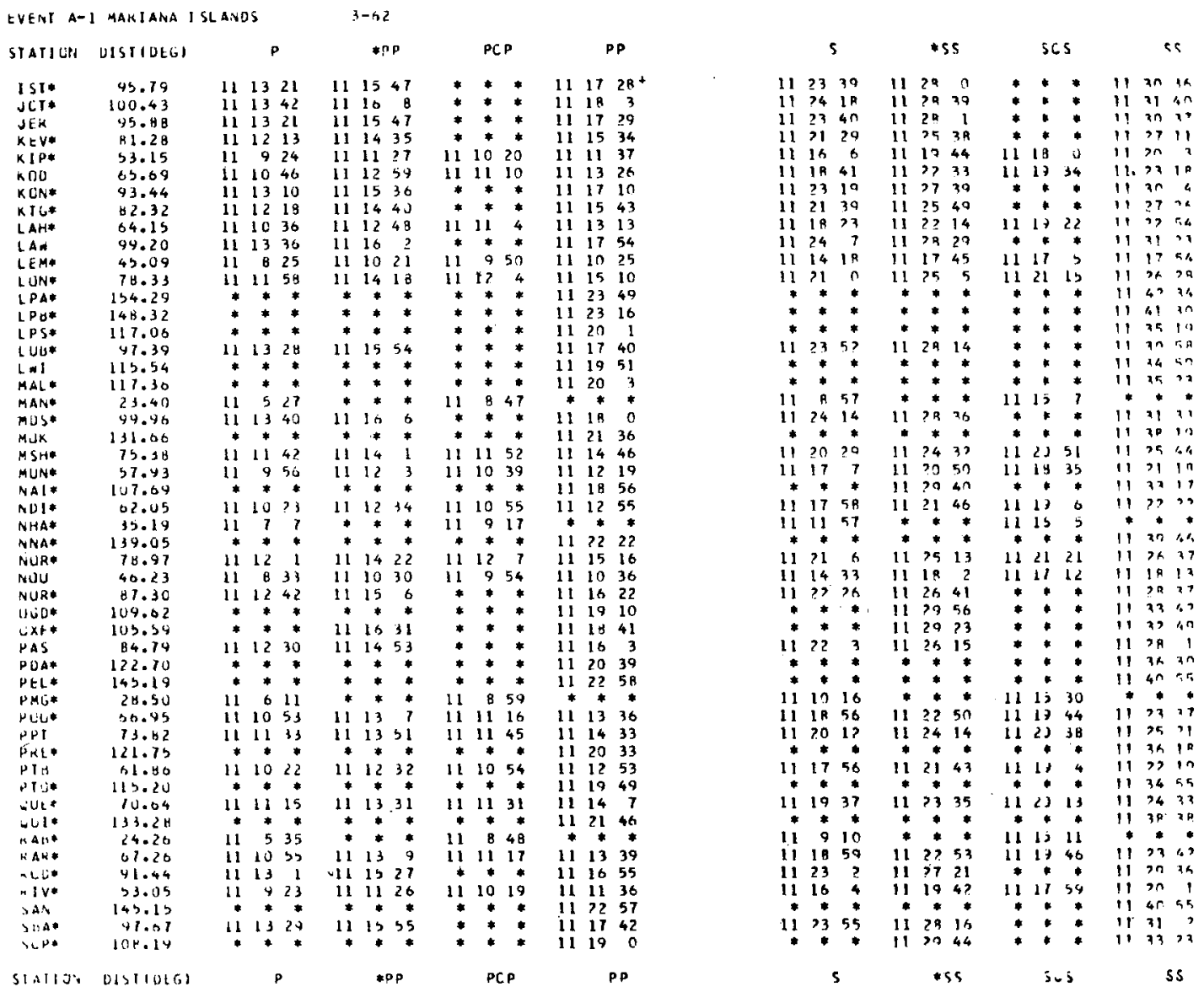

FIg. 13. Output of computer routine for calculation of body-wave travel times from a given source to all WWNSS. ${ }^{*} P P=p P$ and $* S S=s S$.

this relatively large statistical sample, in terms of regional stress patterns, depth dependence of source parameters and global stress fields-has not yet borne the desired fruits.

The method of amplitude equalization, described earlier in connection with the reduction of surface wave data, is also applicable to isolated signals of body waves.

The latent potentialities of body waves lie in their ability to be commensurate with smaller source dimensions and in their prominence on seismograms at most epicentral distances and for a wide magnitude range. This makes them an excellent tool for the study of deep and intermediate earthquakes.

Assuming the validity of ray theory, and considering the Earth's mantle as a linear 
system, we may look upon the spectrums of $P$ and $S$ pulses at the far field as a product of a number of factors which depend on the history of the signal. That is, we may trace the ray back from the station to the source and correct, one by one, for all the factors which took part in shaping the waveform of the signal. These factors are: (1) attenuation and divergence in a spherical Earth; (2) filtering due to crustal heterogeneity; (3) filtering due to the recording instrument. The amplitude equalization procedure is outlined in Figure 14. Its details have already been discussed by Ben-Menahem, Smith and Teng (1965).

BODY-WAVE ANALYSIS PROGRAM PT. II-SOURCE MECHANISM

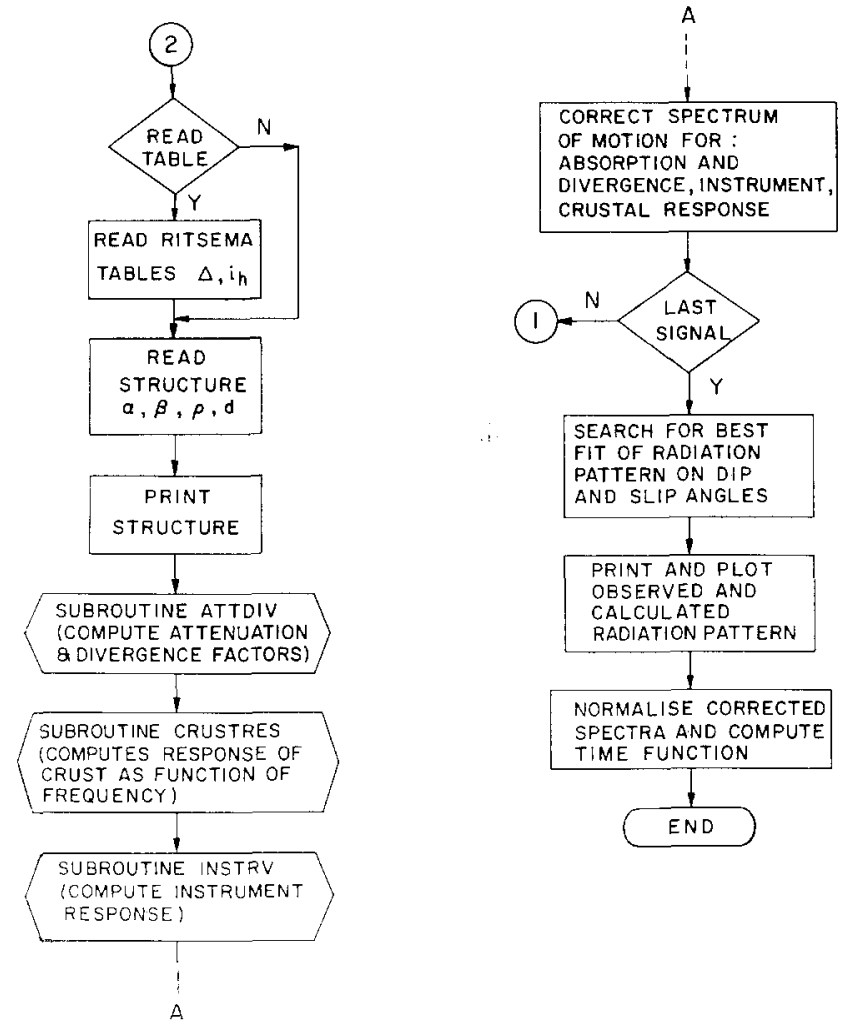

FIG. 14. Flow diagram for routine analysis of isolated body wave signals.

Using the theory expounded therein, the ray-theoretical spectral displacements of $P$, $S H$ and $S V$ waves from shear faults at the far field are recast in the following dimensionless form,

$$
\begin{gathered}
\frac{U_{p}(\omega)}{U_{0}(\omega)}=\left[\frac{d s}{4 \pi a^{2}}\right]\left[\frac{1-2 \sigma_{s}}{1-\sigma_{s}}\left(k_{p} a\right)\right] \frac{e^{-\omega g_{p}(\Delta, h)}}{\sqrt{\sin \Delta}} \sqrt{\left(\frac{\sin i_{h}}{\cos i_{0}} \frac{d i_{h}}{d \Delta}\right)_{p}} \\
\cdot\left\{b_{0} P_{2}{ }^{0}\left(\cos i_{h}\right)+b_{1} P_{2}{ }^{1}\left(\cos i_{h}\right)+b_{2} P_{2}{ }^{2}\left(\cos i_{h}\right)\right\} e^{i \Phi p(\omega)} \\
\frac{U_{S V}(\omega)}{U_{0}(\omega)}=\left[\frac{d s}{4 \pi a^{2}}\right]\left[k_{s} a\right] \frac{e^{-\omega g_{s}(\Delta, h)}}{\sqrt{\sin \Delta}} \sqrt{\left(\frac{\sin i_{h}}{\cos i_{0}} \frac{d i_{h}}{d \Delta}\right)_{s}} \\
\cdot\left\{c_{0}+c_{1} P_{2}{ }^{1}\left(\cos i_{h}\right)+c_{2} P_{2}{ }^{2}\left(\cos i_{h}\right) e^{i \Phi_{S V}(\omega)}\right.
\end{gathered}
$$




$$
\begin{aligned}
\frac{U_{s H}(\omega)}{U_{0}(\omega)}=\left[\frac{d s}{4 \pi a^{2}}\right]\left[k_{s} a\right] \frac{e^{-\omega g_{s}(\Delta, h)}}{\sqrt{\sin \Delta}} \sqrt{\left(\frac{\sin i_{h}}{\cos i_{0}} \frac{d i_{h}}{d \Delta}\right)_{s}} \\
\cdot\left\{d_{0} P_{1}^{0}\left(\cos i_{h}\right)+d_{1} P_{1}{ }^{1}\left(\cos i_{h}\right)\right\} e^{i \Phi_{S H}(\omega)}
\end{aligned}
$$

where

$$
\begin{aligned}
& g_{p}(\Delta, h)=\frac{1}{2} \int_{\text {ray }} \frac{\eta^{2}}{\sqrt{\eta^{2}-p^{2}}} \cdot \frac{d R}{R Q_{p}(R)} \\
& g_{s}(\Delta, h)=\frac{1}{2} \int_{\text {ray }} \frac{\eta^{2}}{\sqrt{\eta^{2}-p^{2}}} \cdot \frac{d R}{R Q_{s}(R)}, \quad \eta=\frac{R}{v(R)} \\
& b_{0}=\frac{1}{2} \sin \lambda \sin 2 \delta \quad d_{0}=q_{L} \quad c_{0}=q_{R} \\
& b_{1}=\frac{1}{3} q_{R} \quad d_{1}=-P_{L} \quad c_{1}=-b_{0}-\frac{1}{3} P_{R} \\
& b_{2}=-\frac{1}{6} P_{R} \quad c_{2}=-\frac{2}{3} q_{R}
\end{aligned}
$$

$q_{R}, P_{R}, q_{L}, P_{L}$-Defined in equations (3) and (6).

These dimensionless displacement ratios can serve as an appropriate model for spectral observations which have been corrected for the effects of the recording instrument and for the distortion due to the crustal layering at the recording station.

Figure 15 shows a sample of the processing routine for $P$ waves recorded at PMG from a deep shock in the Java Sea. The crustal structure at the station has been simulated by a Gutenberg model for an upper mantle with a low-velocity layer. The column $A(\omega)$ gives the Fourier amplitude of the original signal. The next column shows the instrumental amplitude response (multiplied by $\omega_{0}$ ) for a Press-Ewing velocityseismograph with a pendulum period of $30 \mathrm{sec}$ and a galvanometer period of $100 \mathrm{sec}$, at critical damping and zero coupling. The column $\operatorname{ACR}(\omega)$ gives the Haskell crustal response amplitude factor (Ben-Menahem et al, 1965) for the chosen crustal profile. $\mathrm{AD}(\omega)$ is the total diminution factor of the $P$-wave amplitude due to both physical attenuation and geometrical divergence in a spherical Earth model. The function $g(\Delta, h)$ has been computed on the basis of $Q$-data given in Anderson et al. (1965). In. the next column $A_{0}(\omega)=A(\omega) /[\operatorname{AINST}(\omega)][\operatorname{ACR}(\omega)][\operatorname{AD}(\omega)]$. Also PHI $(\omega)$ is the Fourier phase of the original signal. PHINS $(\omega)=$ Fourier phase advance of the seis- 
mograph system in circle units. PHICR $(\omega)=$ Haskell's crustal response phase. PHID $(\omega)=\omega\left(\Delta / c-t_{0}\right), \Delta$ being the epicentral distance in $\mathrm{km}, c$ is the phase velocity of the signal in $\mathrm{km} / \mathrm{sec}$, assumed to be common to all the modes which constitute the isolated signal, and $t_{0}$ is the difference in time (seconds) between the time of origin and the first arrival of the pulse. Finally in the last column we have:

$$
\operatorname{PHIO}(\omega)=\operatorname{PHI}(\omega)-\operatorname{PHINS}(\omega)-\operatorname{PHICR}(\omega)+\operatorname{PHID}(\omega) .
$$

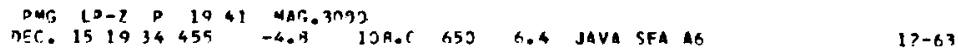

BJOY WAVES INCIDENT ON SJRFACE LAYERING;

6 LAYERS ALDHA RETA PHO MI

PACIFI: GJTEYAERG LOW VELOCITY LAYER I VH-CUTENAEQG CONTINF

$\begin{array}{ccccc}\text { TTY LAYER I VH-CUTENAEQG CONTINF } & & \\ 6.0305 & 3.5300 & 2.7800 & 34.6413 & 22.0300 \\ 6.7003 & 4.4900 & 3.0000 & 60.4803 & 15.0000 \\ 8.0005 & 4.6000 & 3.3300 & 70.4628 & 13.0000 \\ 7.8403 & 4.4905 & 3.2500 & 67.5363 & 75.0000 \\ 7.8400 & 4.3800 & 3.3700 & 64.6514 & 50.0000 \\ 8.0205 & 4.3800 & 3.4200 & 45.4106 & 1000\end{array}$

\begin{tabular}{|c|c|c|c|c|c|c|c|c|c|c|c|c|c|c|c|c|c|c|c|}
\hline \multicolumn{2}{|c|}{ 141 } & \multicolumn{2}{|c|}{ AINSIWI } & \multicolumn{2}{|c|}{ ACR R WI } & \multicolumn{2}{|c|}{$A B(W)$} & \multicolumn{2}{|c|}{$A O I N 1$} & \multicolumn{2}{|c|}{ PHI $\mid W]$} & \multicolumn{2}{|c|}{ PHIIVSIWI } & \multicolumn{2}{|c|}{ pHICR|w| } & \multicolumn{2}{|c|}{ PHIDIWI } & \multicolumn{2}{|c|}{$O H I \cap(H)$} \\
\hline $5.70 .22 \equiv$ & -1 & & & & 3 & $.4274 \mathrm{~F}$ & -4 & & 0 & & 0 & & $n$ & $.8115 \mathrm{~F}$ & -1 & & 0 & $1115 \mathrm{~F}$ & -1 \\
\hline & -1 & $5.267 \mathrm{BF}$ & -1 & 1.5A?7E & כ & $.421 \mathrm{AF}$ & -4 & $9.9615 E$ & 2 & $9.8943 F$ & -2 & -1.4400 & 0 & & -1 & $-2.2208 E$ & -1 & & -1 \\
\hline & $?$ & 4.1 & 0 & $.5 \mathrm{ASSE}$ & 3 & $63 \mathrm{~F}$ & -4 & & 3 & $-4.5877 E$ & -1 & & 0 & 7.37 คF & $-i$ & & -1 & $3) \%$ & -1 \\
\hline & $\mathfrak{3}$ & & 1 & $3 F$ & 0 & ORE & -4 & $5 F$ & 3 & -4.2 & & & 0 & $7.3172 \mathrm{E}$ & $-i$ & $-6.6625 E$ & $-i$ & & -1 \\
\hline & 0 & 3.2 & 1 & & 3 & & -4 & & & -3.9 & -1 & & 0 & & -1 & & -1 & 45 & -1 \\
\hline & 1 & 6.1 & 1 & $54 \mathrm{~F}$ & 2 & AF & -4 & & 2 & -3.6 & -1 & -9.7 & -1 & $4 \mathrm{~F}$ & -1 & -1 & 0 & 5 & \\
\hline & 1 & $1373 F$ & $?$ & & 3 & $943 E$ & -4 & & $?$ & -3.4 & -1 & -8.9 & -1 & $95 F$ & -1 & & 0 & & \\
\hline $4=$ & 1 & $1.5949 \mathrm{~F}$ & $?$ & $277 \mathrm{~F}$ & o & $689 F$ & -4 & & 2 & $-3.1510 \mathrm{E}$ & -1 & $-6.9 A ? 1 E$ & -1 & $7.0533 \mathrm{~F}$ & -1 & $-1.55 a$ & $u$ & & \\
\hline $49:$ & 1 & $2 . ? 00 \mathrm{LIF}$ & 2 & $15 E$ & ? & A35E & -4 & $298 E$ & 2 & $-2.8 R 24 E$ & -1 & $-5.7 !$ & -1 & $6 \mathrm{FF}$ & -1 & -1.77 & 0 & 10 & \\
\hline $59 \Xi$ & 1 & $3.1419 \mathrm{~F}$ & 7 & $58 F$ & 7 & $781 \mathrm{~F}$ & -4 & $14 \mathrm{~F}$ & 2 & -2.6 & -1 & -4.56 & -1 & IF & -1 & & c & & \\
\hline 77 & 1 & 4. 12ABE & 2 & $36 E$ & 3 & $27 F$ & -4 & QF & $?$ & -2 & -1 & -3. & -1 & $5 F$ & -1 & -2 & 0 & PF & \\
\hline RL: & 1 & $407 F$ & $?$ & & 7 & & -4 & & 2 & & -1 & $-?$ & -1 & $7 F$ & -1 & & 0 & & \\
\hline $69 \equiv$ & 1 & $0.4945 E$ & $?$ & $F$ & 3 & & -4 & IF & $?$ & $3 E$ & -1 & -1 & -1 & $37 F$ & -1 & -2 & 0 & AF & \\
\hline & 1 & 7.9 & $?$ & & 7 & & -4 & & $c$ & & -1 & -3 & - ? & & -1 & & 0 & & \\
\hline $4=$ & 1 & $9.35 .79 \mathrm{~F}$ & 2 & ef & 3 & $5 E$ & -4 & & $?$ & -1 & -1 & DF & $-?$ & IE & -1 & & 0 & ar & \\
\hline & 1 & $1.0849 \mathrm{~F}$ & 3 & & ) & $2 \mathrm{E}$ & -4 & & 2 & -1. & -1 & & -1 & $7 F$ & -1 & & J & -4.9 & \\
\hline$\equiv$ & 1 & 1. & 3 & & $?$ & $Q E$ & -4 & & & -9. & $-?$ & AF & -1 & $1 F$ & -1 & & 0 & .5 & \\
\hline $9=$ & 1 & 1.41 & 3 & $E$ & 3 & $7 E$ & -4 & IE & $?$ & -5.9 & -2 & & -1 & $2 \mathrm{~F}$ & -1 & & 0 & & \\
\hline A, 9 & 1 & & 3 & & 1 & & -4 & & , & & -2 & & -1 & & & & 0 & & \\
\hline 9.4 & 1 & 1. & 3 & E & ? & $3 \mathrm{~F}$ & -4 & & , & $-h . Q$ & -3 & & -1 & $B F$ & -1 & & 0 & F & \\
\hline & 1 & & $?$ & & 9 & & -4 & & ? & & -2 & & -1 & & & & 0 & & \\
\hline$\vdots$ & $?$ & ? & 3 & $\varepsilon$ & 3 & SF & -4 & & 2 & F & -2 & & -1 & $2 F$ & -1 & -4 & & $f$ & \\
\hline & 2 & & 3 & & 3 & & -4 & & , & $F$ & -2 & & -1 & & -1 & -4 & 0 & 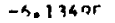 & \\
\hline $4=$ & $?$ & 2 & 3 & 1. & $?$ & $8 F$ & -4 & & 2 & & $-?$ & & -1 & & -1 & -5 & & $-t$ & \\
\hline & 2 & & 3 & & 3 & & -4 & & ? & & -1 & & -1 & & -1 & & 0 & $=$ & \\
\hline & $?$ & 2 & 3 & $\mathbf{F}$ & 3 & $6 F$ & -4 & & , & FF & -1 & & -1 & $7 F$ & -1 & & & -10 & \\
\hline & $?$ & & 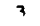 & $1039 \mathrm{~F}$ & 3 & $996 F$ & -4 & $45 \mathrm{DF}$ & ? & $1.4892 \mathrm{~F}$ & -1 & $1 \mathrm{~F}$ & 0 & $2 F$ & -1 & & 0 & $-7.1674 r$ & \\
\hline $33=$ & ? & 3.1 & 3 & 1.7779E & 3 & I AAE & -4 & & ? & & -1 & & $n$ & & -1 & & 6 & -7.42 & \\
\hline $25=$ & 2 & & 3 & 1.74795 & ? & $95 \mathrm{~F}$ & -4 & SF & ? & $94 \mathrm{~F}$ & -1 & & 0 & $29 F$ & -1 & & j & 7.67 & \\
\hline & $?$ & 49 & 3 & $1.7141 F$ & 3 & $6 \mathrm{~F}$ & -4 & & 7 & & -1 & & 0 & & & & 0 & $F$ & \\
\hline $1.0641 \equiv$ & $?$ & & 3 & 1.677 & 1 & $96 F$ & -4 & $6 F$ & ? & 2.19915 & -1 & $5 F$ & $r$ & 295 & -1 & & 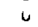 & $F$ & \\
\hline & ? & $3.7093 \mathrm{~F}$ & 3 & 1.63 & ? & $4 \mathrm{HF}$ & -4 & & , & & -1 & & 0 & 4. A & & & & & \\
\hline & $?$ & $3.9479 F$ & 3 & & $?$ & & -4 & & , & $2.5757 F$ & -1 & & $n$ & $4.81 ? 2 F$ & -1 & & 0 & & \\
\hline & $?$ & $4.0910 \mathrm{~F}$ & 3 & $1.5507 \mathrm{~F}$ & $?$ & SE & -4 & & ? & & -1 & & 0 & 4.7 & & & & ir & \\
\hline & $?$ & $4.2314 F$ & 2 & 10.2 & 2 & $1.2499 \mathrm{~F}$ & -4 & 1.32 & 2 & 2.94 & -1 & & $n$ & 4.6 & - & PE & is & .12 & \\
\hline & $?$ & $4.3610 F$ & 3 & 1.49 & 7 & 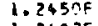 & -4 & & 2 & & -1 & & $?$ & & & & & & \\
\hline & 3 & & & & 2 & & -4 & & ? & & -1 & & 0 & $4.5 ? 03 F$ & - & & & Ione & \\
\hline & 2 & 5 & $3^{3}$ & 40 & 3 & $1.2353 E$ & -4 & 1. & $?$ & $5 F$ & -1 & $1.5937 \mathrm{~F}$ & 0 & 4. & & $1 \mathrm{E}$ & & 15 & \\
\hline & & F & & $.3737 \mathrm{~F}$ & & $1.236 .5 F$ & & $1.3704 \mathrm{~F}$ & & $5 F$ & & $S 3 R]$ & & 4.4167 & -1 & 99? E & & TPF & \\
\hline
\end{tabular}

FIG. 15. Output of computer routine for amplitude and phase equalization of body wave spectrums. Frequency range extends from $f_{0}=.0005 \mathrm{cps}$ (top) to $f=.019 \mathrm{cps}$ (bottom) at intervals of $\Delta f=.0005 \mathrm{cps}$.

Given $\Delta$ for a station, $i_{h}$ is then obtained by a linear interpolation from the $\Delta-i_{h}$ tables (Ritsema, 1958).

For any given seismic event, the equalized amplitudes $A_{0}(\omega)$ are evaluated for a 
network of stations around the source. A search is then conducted for a best fit to a theoretical source model along the same lines indicated previously for surface waves. Results for a certain deep shock are presented in Figure 16. Here, the computer preferred a model of dip-slip shear-type fault.

Figure 17 indicates the effect of the crustal structure at the recording station on the process of equalization. No significant difference is noticed between the two structures

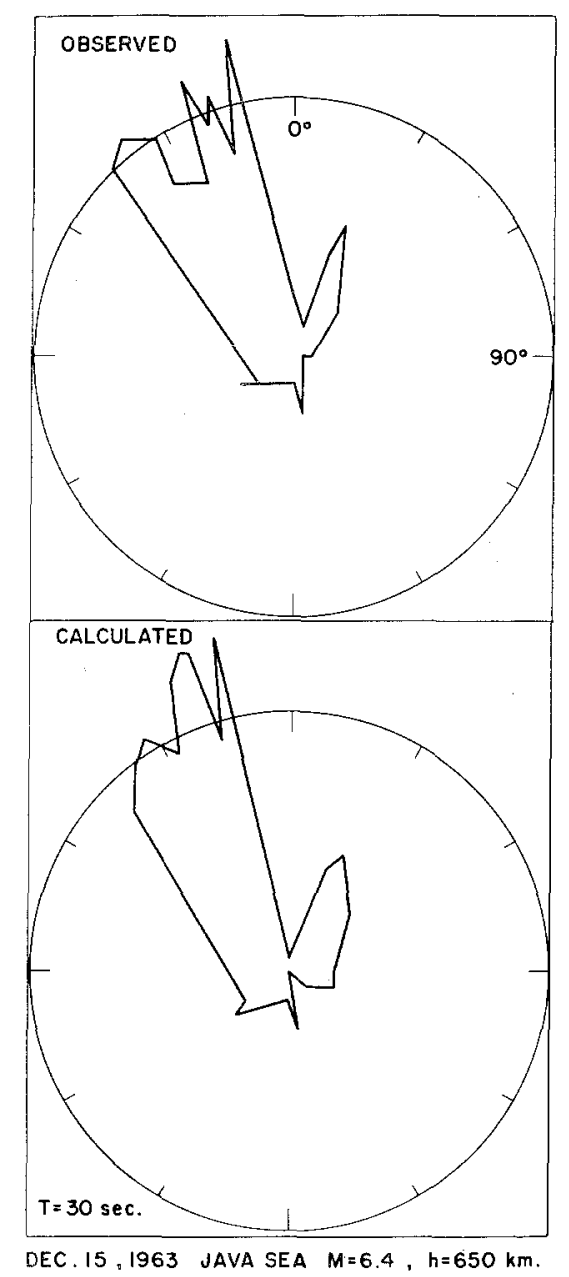

Fig. 16. Results of search for best fit of observed and calculated radiation patterns of $P Z$ waves from a deep shock. Amplitudes are plotted as function of azimuth from north $\left(0^{\circ}\right)$ toward east $\left(90^{\circ}\right)$.

at periods greater than 25 sec. The Dugway-Golden crustal structure was given by Steinhart and Meyer (1961).

According to first-order ray theory, the radiation patterns of the direct arrivals from shear and tensile faults are frequency-independent down to frequencies of 0.01 cps. Thus, any dependence of the amplitudes on frequency, after correcting them for the radiation patterns, must be due to either the time function at the source or the finiteness of the source, or both.

Kasahara (1963), Teng and Ben-Menahem (1965) and Chander and Brune (1965) 


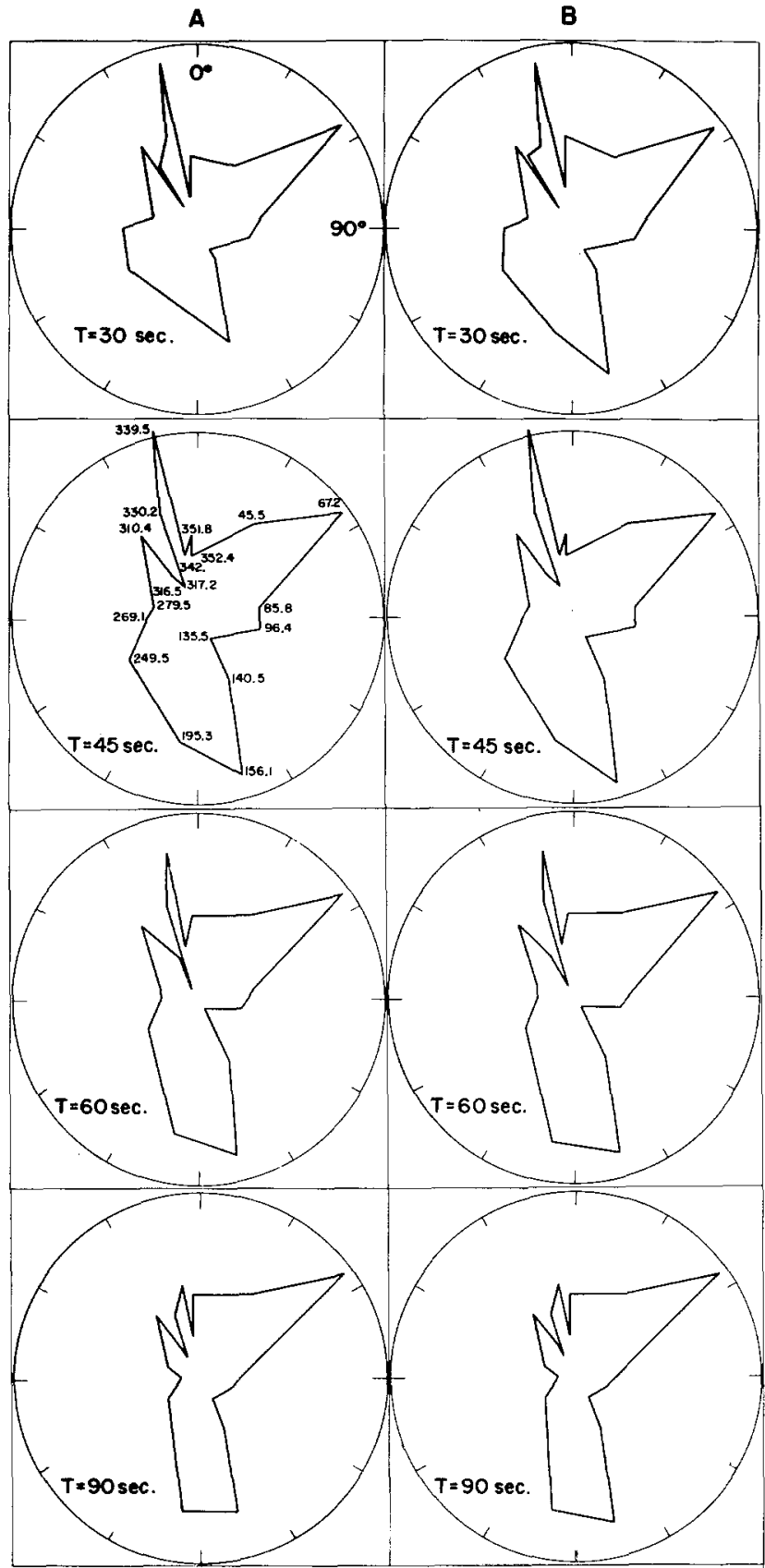

OCT $.18,1964$ BANDA SEA $M=5.8, h=574 \mathrm{~km}$.

A: GUTENBERG LOW VELOCITY LAYER MODEL

B:DUGWAY-GOLDEN CRUSTAL MODEL

FIG. 17. Observed radiation patterns of $P Z$ waves for four periods and two models of crustal strueture. Numerals indicate azimuth in degrees measured clockwise from north $\left(0^{\circ}\right)$.

have shown that the size of the source of deep shocks $(M<7)$ is at most of the order of a few tens of kilometers. Long period body waves in the period range $10<T<100$ sec will not carry, therefore, retrievable information about the source dimensions of deep shocks in the intermediate magnitude range. It is expected therefore that $U_{0}(f)$, 


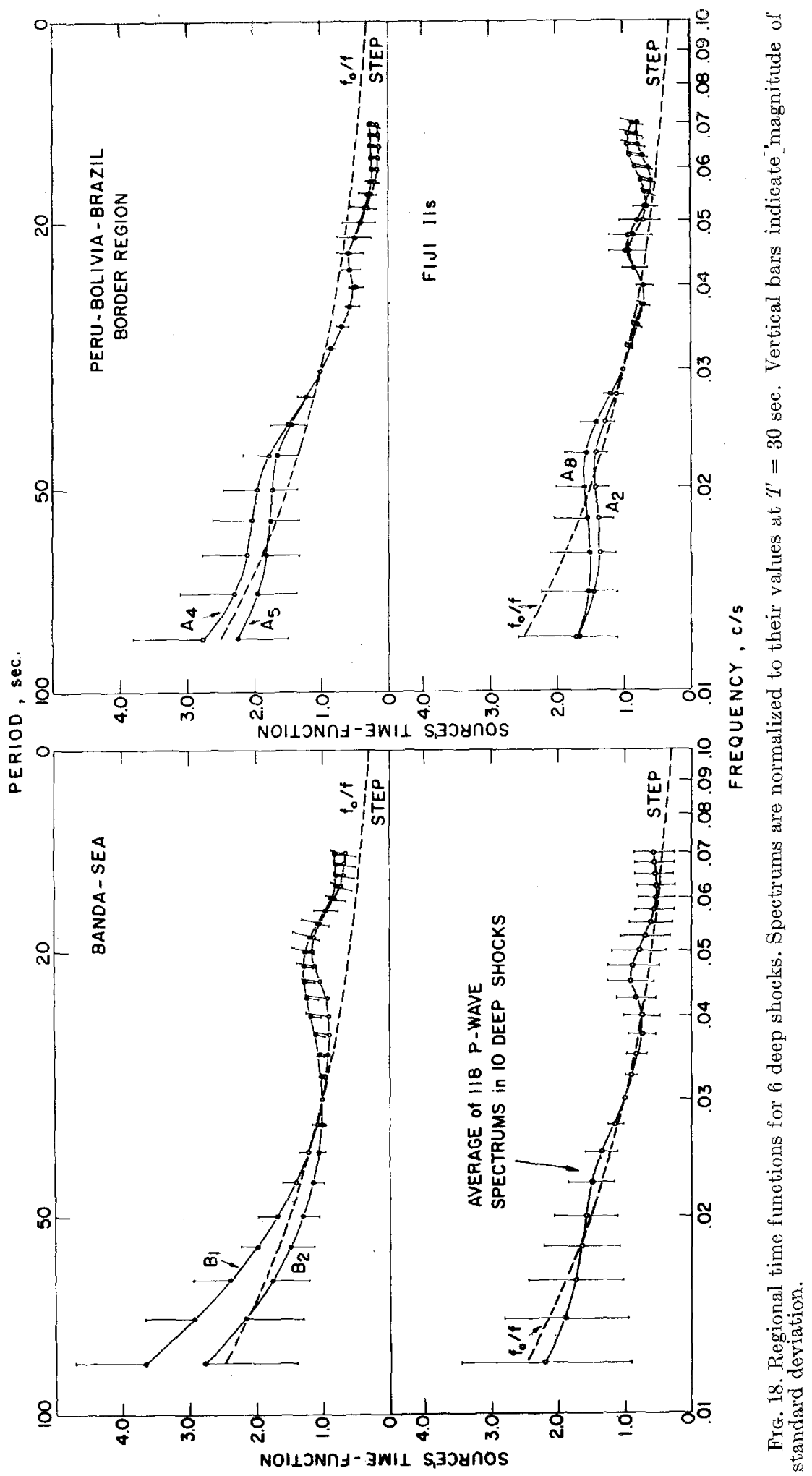


as derived experimentally from the observed spectrums, will render the overall average time dependence at the source. Figure 18 shows the function $U_{0}(f) / U_{0}\left(f_{0}\right)$ for six deep shocks (Table 1 ) as compared to the curve $f_{0} / f$ appropriate for a Heaviside unit stepfunction. $f_{0}=\frac{1}{30} \mathrm{cps}$.

TABLE 1

\begin{tabular}{|c|c|c|c|c|c|c|c|c|c|c|}
\hline Index & Date & $\begin{array}{l}\text { Time of } \\
\text { Origin } \\
\text { (GMT) }\end{array}$ & $\begin{array}{c}\text { Lati- } \\
\text { tude } \\
\text { Degrees }\end{array}$ & $\begin{array}{l}\text { Longi- } \\
\text { tude } \\
\text { Degrees }\end{array}$ & $\underset{\mathrm{km}}{\text { Depth }}$ & $\begin{array}{c}\text { C. G. S. } \\
\text { Magnitude }\end{array}$ & Location & $\begin{array}{c}\text { Dip } \\
\text { Degrees }\end{array}$ & $\underset{\text { Segrees }}{\text { Slip }}$ & $\begin{array}{l}\text { Method of } \\
\text { Analysis }\end{array}$ \\
\hline$A-1$ & March 7, 1962 & 11-01-04 & $19.2 \mathrm{~N}$ & $145.1 \mathrm{E}$ & 685 & 7 & Mariana Isl. & 38 & 72 & Body Waves \\
\hline$A-2$ & Sept. 9,1962 & $15-43-57$ & $21.2 \mathrm{~S}$ & $179.1 \mathrm{~W}$ & 612 & $6 \frac{1}{2}$ & Fiji Islands & 106 & 116 & Body Waves \\
\hline $\mathrm{A}-3$ & Dec. 8, 1962 & $21-27-22$ & $25.8 \mathrm{~S}$ & $63.4 \mathrm{~W}$ & 620 & $6 \frac{3}{4}-7$ & Argentina & 78 & 98 & Body Waves \\
\hline$A-4$ & Aug. 15, 1963 & $17-25-06$ & $13.8 \mathrm{~S}$ & $69.3 \mathrm{~W}$ & 543 & 6 & $\begin{array}{l}\text { Peru- } \\
\text { Bolivia }\end{array}$ & 45 & 90 & $\begin{array}{l}\text { B-W \& Free } \\
\text { Oscillation } \\
\text { (1) }\end{array}$ \\
\hline$A-5$ & Nov. 9, 1963 & $21-15-30$ & $9.0 \mathrm{~s}$ & $71.5 \mathrm{~W}$ & 600 & 6 & West Brazil & 44 & 97 & Body Waves \\
\hline$A-6$ & Dec. 15, 1963 & $19-34-45$ & $4.8 \mathrm{~s}$ & $108.0 \mathrm{E}$ & 650 & $6 \frac{1}{2}$ & Java & 55 & 70 & Body Waves \\
\hline B-1 & Oct. 18, 1964 & $12-32-24$ & $7.0 \mathrm{~S}$ & $124,0 \mathrm{E}$ & 574 & 6 & Banda Sea & 43 & 118 & Body Waves \\
\hline A-8 & Dec. 28, 1964 & $16-16-11$ & $22.1 \mathrm{~S}$ & $179.6 \mathrm{~W}$ & 611 & $6 \frac{1}{4}$ & $\begin{array}{l}\text { South of } \\
\text { Fiji }\end{array}$ & 90 & 90 & Body Waves \\
\hline A-10 & Nov. 3,1965 & $01-39-02$ & $9.1 \mathrm{~s}$ & $71.4 \mathrm{~W}$ & 583 & $6 \frac{x}{4}$ & Peru-Brazil & 49 & 97 & Body Waves \\
\hline B-2 & July 8,1964 & $11-55-39$ & $5.5 \mathrm{~S}$ & $129.8 \mathrm{E}$ & 165 & $6 \frac{1}{2}$ & Banda Sea & 60 & 90 & Body Waves \\
\hline B-3 & March 21, 1964 & $03-42-19$ & $6.4 \mathrm{~S}$ & $127.9 \mathrm{E}$ & 367 & $7-7 \frac{1}{2}(\mathrm{PAS})$ & Banda Sea & $45(90)$ & $0(45)$ & Body Waves \\
\hline F-1 & July 6, 1962 & $23-05-32$ & $36.6 \mathrm{~N}$ & $70.4 \mathrm{E}$ & 218 & $6 \frac{3}{4}-7$ & Hindu Kush & 78 & 90 & $\begin{array}{l}\text { Rayleigh } \\
\text { Waves (2) }\end{array}$ \\
\hline$E-2$ & Jan. 28,1964 & $14-09-17$ & $36.5 \mathrm{~N}$ & $70.9 \mathrm{E}$ & $|192-207|$ & $6-6 \frac{1}{a}$ & Hindu Kush & 71 & 80 & $\begin{array}{l}\text { Initial Mo- } \\
\text { tions (3) }\end{array}$ \\
\hline
\end{tabular}

(1) Chander and Brune (1965)

(2) Alsop and Brune (1965)

(3) Hedayati and Hirasawa (1966)

\section{Some Applications}

(1) A tsunami warning system. The efficient generation of tsunamis by some major earthquakes lends support to an hypothesis that the size of the source, the orientation of the displacement vector, the source's time function, and the overall duration of the event may play an important role in the energy coupling between the disturbed ocean floor and the fluid medium above it. Most of the major shocks which occurred in the circum-Pacific belt produced devastating tsunamis on the shores of the Pacific. Although the generation mechanism of tsunamis is not well understood, it is reasonable to expect that the phenomenon is governed by some favorable combination of the seismic source parameters with the submarine topography at the focus.

The surface-waves processing routine, described in a previous chapter, may serve as a useful tool for a preliminary study of a possible correlation of seismic source parameters to the intensity of an associated tsunami, and later also as part of the overall warning system itself. The preliminary study may be based on records chosen from the archives of the WWNSS. An effort must be made to relate the source elements to the tsunami's energy content. If some correlative patterns are discovered which agree with the findings of other research groups in this diversified project, then an operational procedure should be set up and tested. We are suggesting the following warning system: A network of some 10 stations on the Pacific Coast could be established. Each station should be equipped with a triaxial displacement seismograph with an ultra long-period response. Data from these stations will be assumed to flow by telemetry to a seismic computer center at Hawaii, say.

Assuming the availability of $R_{1}, G_{1}, R_{2}$ and $G_{2}$ waves from a seismic event, these 
waves will be analyzed and equalized at the central station. Their radiation patterns, directivities, time functions and fault elements will be found and then interpreted in terms of the parameters of the tsunami source.

Relative travel times of tsunami waves and mantle surface waves are relevant to the project: the average distance to Hilo from the ocean's periphery is about $60^{\circ}$. The corresponding tsunami travel time for that distance is about 7 hours. $R_{1}$ covers this distance in about 30 minutes. However, the Airy-phase of $R_{2}$ will spend $2 \frac{1}{2}$ hours to reach Hilo along the major arc. The Airy-phase of $R_{3}$ arrives an hour later. From the source-mechanism point of view, best results are usually obtained with $R_{2}, R_{3}, G_{2}$ and $G_{3}$.

(2) Global study of deep shocks. The most obvious application of our program is for regional source studies, that is, the assignment of a set of parameters to a given region. We have started with deep shocks since we believe that there, the regionalization is both easier and more meaningful.

Data of the WWNSS were used for a comparative study of very deep shocks in the CGS magnitude range $6-7$. Out of a total of 45 events intended for this study, we have concluded the study of 9 shocks at Fiji, Mariana, Java, Japan, Peru and Brazil. Each event has been studied from the spectrums of an average of 10 stations around it with a sufficient azimuthal coverage.

Table 1 presents 12 fault-plane solutions obtained by the spectral method and an additional solution obtained by the initial motion method. Eleven of these, including 9 shocks in the depth range $500-700 \mathrm{~km}$, were obtained by us, using our composite machine program described earlier. In all these cases a full agreement was obtained between initial-motion and spectral solutions. In the case of A-4 our result agrees with that of Alsop and Brune (1965). Here again, the solutions are not unique. This is reflected in the symmetry relations of the radiation patterns for $P$ waves. Denoting by $A(\delta, \lambda, \theta)$ the spectral amplitude of a $P$ wave recorded at an azimuth of $\theta$ degrees with angle of emergence $i_{k}$ from a displacement source with elements $\delta$ and $\lambda$, we find from equations (8) to (13),

$$
\begin{gathered}
A(0,0 ; \theta)=A(0,45 ; \theta+45)=A(0,90 ; 90-\theta)=-A(90,90 ; \theta+90) \\
A(45,0 ; \theta)=A(90,-45 ; 90-\theta) \\
A(45,90 ; \theta)=A(45,90 ; 180-\theta) \\
A(\lambda+180)+A(\lambda)=0
\end{gathered}
$$

all angles are expressed in degrees. The similarity to equations $(7)$ is obvious.

In general, for each solution $(\delta, \lambda)$ there may be one or more corresponding pairs which will give the same radiation pattern for $P$ waves. This is a direct consequence of equations (8) to (10), and it results from the non-uniqueness of the trigonometric functions appearing therein.

Two types of solutions appear for the deep shocks: A dip-slip motion on a vertical fault (A-2, A-3, A-8, F-1, F-2) and a dip-slip motion on a $45^{\circ}$ dipping fault (A-1, A-4, A-5, A-6, A-10, B-1). These two solutions do not correspond to two possible interpretations of the data, as is obvious from the previous symmetry relations. Each one of them was accompanied by a different solution which was discarded on the basis of $S$ wave amplitudes and initial motions. Note the interesting feature that the first group 
has its foci to the north of the Tropic of Cancer and to the south of the Tropic of Capricorn while the foci of the second group are confined to the equatorial region between these two parallels.

The dominance of the dip-slip motion for deep shocks in the present sample is in agreement with earlier findings of Ritsema (1964).

Additional support for the dominance of the solution $\delta=45^{\circ}, \lambda=90^{\circ}$ comes from a reinterpretation of first-motion polarity data.

Evison (1967) introduced a useful concept in first-motion theory. He has counted the number of dilatations $\left(N_{d}\right)$ and the number of compressions $\left(N_{c}\right)$ of a given event and defined the polarity as the greater of the two numbers expressed as a percentage of their sum. Examining certain samples of data, he has proposed that earthquakes ought to be classified as dominantly explosive or implosive. His arguments rest on the distribution of first motion polarities of 65 shocks in the period 1955-1962. To explain departures from "all-explosive" or "all-implosive" sources, Evison introduces a possibility of a change of shape at the source for some shocks. Let us assume, contrary to this hypothesis, that the source is not of zero order but rather of the second order, namely a displacement dislocation on a planar fault, the orientation of which is determined by a slip angle $\lambda$, and a dip angle $\delta$. Assume next that the observed first-motions from a given event have been plotted on a Byerly extended distance chart. Restricting ourselves to $P$-wave signals for epicentral distances which are less than $105^{\circ}$, we notice that all the observed points will lie within a circle of radius $d=\cot i_{h}$ where $i_{h}=i_{h}(\Delta)$ is the take-off angle of the $P$ wave ray. According to Ritsema (1958) take-off angles for $\Delta=105^{\circ}$ vary from $i_{h}=153^{\circ}$ at extreme focal depth to $i_{h}=163^{\circ}$ at zero depths. Hence $1.96<|d|<3.27$ on Byerly's extended distance plane.

Further, it is well-known that the nodal lines for $P$ waves from a second order source of the above type consist of two orthogonal circles, one of radius $r=\frac{1}{2} \tan \delta$ and the other of radius $R=\frac{1}{2} \tan \delta^{\prime}$ where $\delta$ and $\delta^{\prime}$ are the dip angles of the fault-plane and the auxiliary plane, respectively. Neglecting the common area of the two circles relative to the sum of their areas and taking the number of dilatations (or compressions) to be proportional to the area which they occupy on the extended distance plane, we may assume that $N_{D}>N_{C}$ and write for the polarity percentage $P$,

$$
\begin{gathered}
P=100\left(\frac{\Gamma}{1+\Gamma}\right) \\
\Gamma(\delta, \lambda)=\frac{N_{D}}{N_{C}}=\frac{4 d^{2}}{\tan ^{2} \delta+\tan ^{2} \delta^{\prime}}-1, \quad \tan \delta^{\prime}=\frac{\sqrt{1-\sin ^{2} \lambda \overline{\sin ^{2} \delta}}}{\sin \lambda \sin \delta}
\end{gathered}
$$

(Ben-Menahem and Harkrider 1964)

It is sufficient to choose $0 \leqq \delta \leqq 90^{\circ}, 0 \leqq \lambda \leqq 180^{\circ}$ since

$$
\Gamma(180-\delta, \lambda)=\Gamma(\delta, 180-\lambda)=\Gamma(\delta, 180+\lambda)=\Gamma(\delta, \lambda) .
$$

The function $\Gamma(\delta, \lambda)$ has been computed for a representative grid of dip and slip angles. The results are shown in Figure 19. The extremal polarity corresponds always to a dip angle of $45^{\circ}$ and a slip angle of $90^{\circ}$. The extremal $\Gamma$ is given by $\left\{2\left[d_{\max }\right]^{2}-1\right\}$. It equals 7 for a focal depth of $650 \mathrm{~km}$ and about 20 for a surface focus. This corresponds to polarities of 88 per cent and 95 per cent respectively.

It is concluded therefore that the data presented by Evison supports the following: 


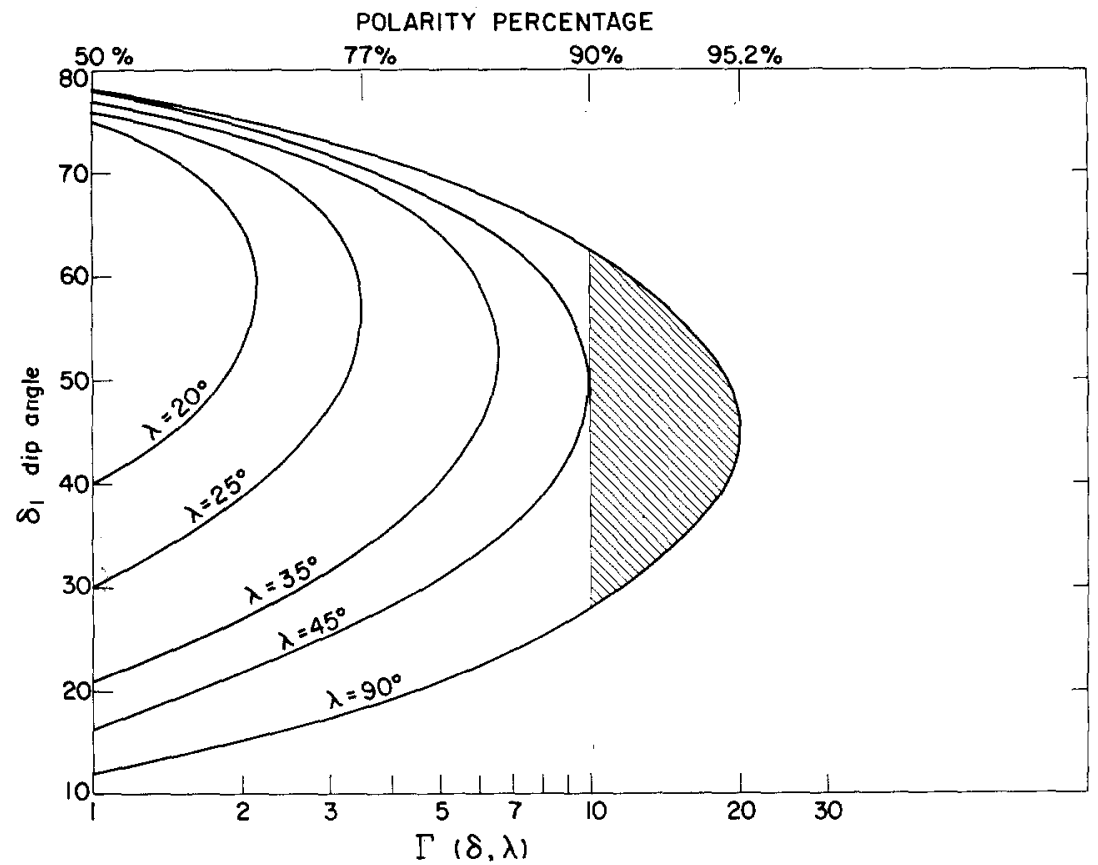

Frg. 19. The dependence of the $P$-wave polarity on the orientation of a surface shear dislocation $\left(\Delta_{\max }=105^{\circ}, h=0\right)$.

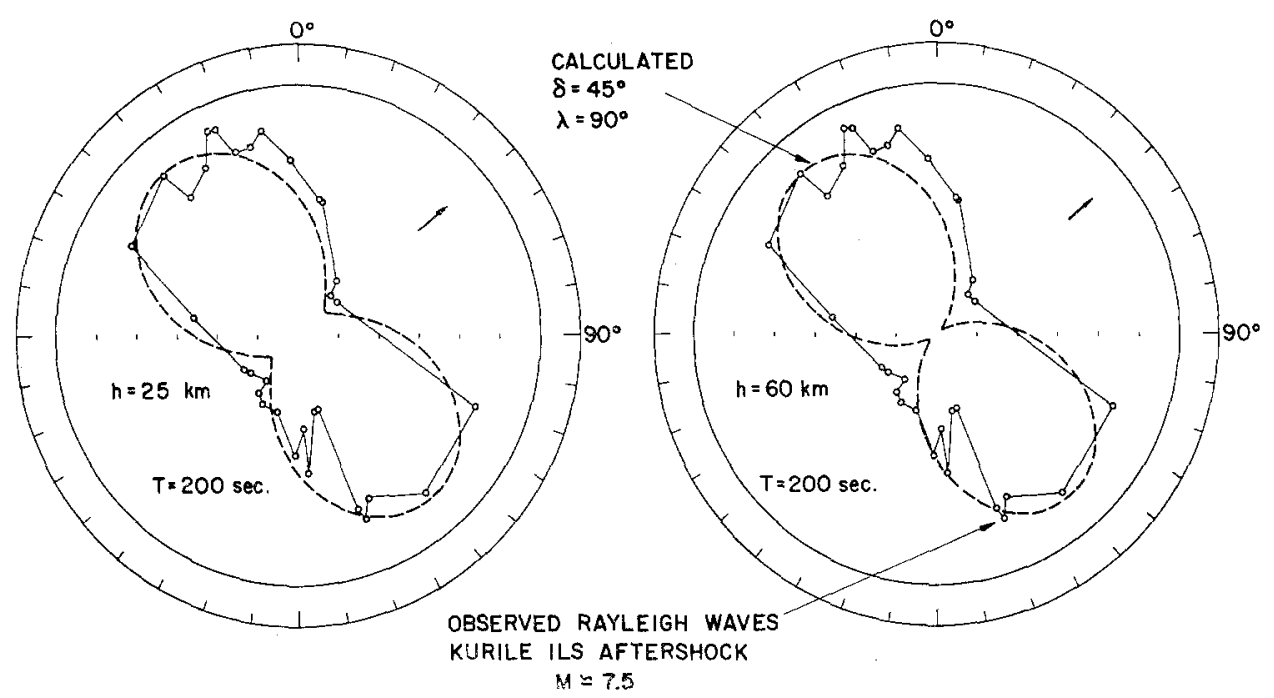

FiG. 20. Depth determination from the radiation pattern of Rayleigh waves $\left(U_{z}\right)$ at the Airy phase

(1) The spatial orientations of shear dislocations are related to the environment of the source.

(2) A majority of the observations are associated with shear faults of the normal (or reverse) type.

(3) Depth determination from modal spectral ratios. Ben-Menahem and Harkrider (1964) have found that the radiation pattern of both Love and Rayleigh waves is diagnostic of the source's depth and that the sensitivity of the patterns to changes in depth depends on the source's depth, frequency and orientation. Some of these effects 


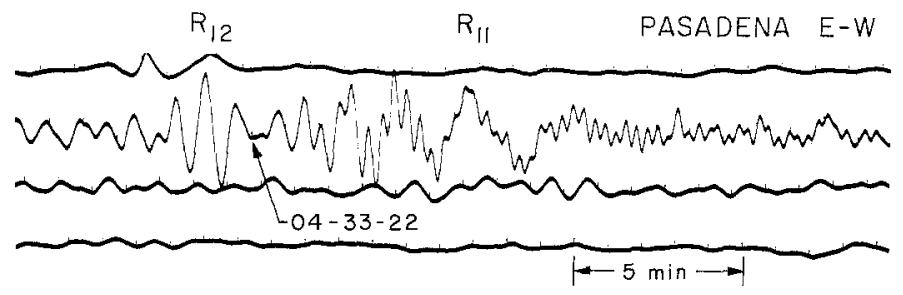

BANDA-SEA $\mathrm{h}=375 \mathrm{~km}$

March $211964 \quad 03-42-20$

$M \sim 6.5$

FIG. 21. A fundamental oceanic Rayleigh wave $\left(R_{11}\right)$ preceded by a second higher Rayleigh mode $\left(R_{12}\right)$. Seismogram is $S H$-free since great circle path of waves coincides with $E-W$ direction at Pasadena. Note oceanic crustal Rayleigh waves riding on $R_{11}$.

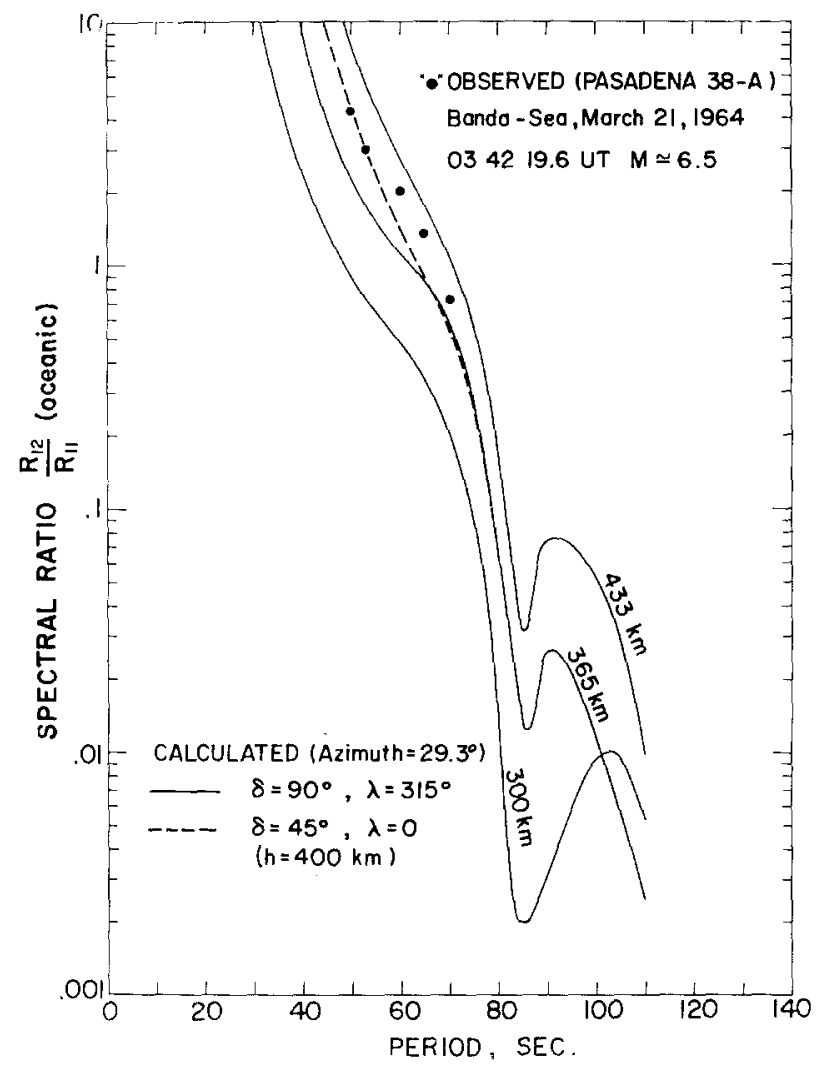

FIG. 22. Depth determination from a modal spectral ratio. Instrumental constants (Gilman, 1960) are $T_{0}=60 \mathrm{sec}, T_{g}=110 \mathrm{sec}, \tau=\mathbf{5 0}$.

are visible in the examples given in Figure 7. The results shown in Figure 20 demonstrate rather clearly the sensitivity of the radiation patterns to source-depth changes. Here, observations favor a depth of $25 \mathrm{~km}$, which also fits the USCGS depth determination, based on $P$-wave arrivals. Calculations based on equation (4) have shown that a shear source with an orientation of $\delta=80^{\circ}, \lambda=90^{\circ}$ has a radiation pattern that is indistinguishable from that of the orientation $\delta=45^{\circ} \lambda=90^{\circ}$ for a shield earth model at shallow source depths. Harkrider (1967) computed spectrums of higher modes of 
Rayleigh and Love waves from point shear-dislocations in a multilayered half-space earth model. Some results based on his calculations are presented in Figures $7^{\mathrm{a}}$ and $7^{\mathrm{b}}$. Spectral ratios of various combinations of higher modes of Rayleigh and Love waves may serve as a useful tool for the determination of the focal depth. An example is shown in Figures 21 and 22, where long-period surface wave signals from a deep shock were used to recover the source's depth from a spectral ratio of $R_{12} / R_{11}$. The source mechanism of the Banda Sea shock has been determined by Teng and Ben-Menahem (1965) from spectral amplitudes of $P$ waves recorded on the WWNSS. It was found then that the solution $\delta=90^{\circ}, \lambda=315^{\circ}$ gave a best fit to the observed radiation patterns. We noticed earlier (equation 7) that the orientations $\delta=90^{\circ}, \lambda=315^{\circ}$ with an azimuth $\theta=\theta_{1}^{\circ}$, will produce an equivalent pattern to that of the orientation $\delta=45^{\circ}$, $\lambda=0^{\circ}$ with an azimuth of $\theta=90^{\circ}-\theta_{1}^{\circ}$. Both cases agree on a focal depth of 400 $\mathrm{km} \pm 30 \mathrm{~km}$ which is consistent with the depth derived through the use of body-wave travel times.

\section{Conclusions}

The future of source mechanism studies will depend on the ability to process a great number of seismic events. Results obtained hitherto by the spectral analyses of the far radiation field of body and surface waves support the following assumptions:

(1) The crust and the upper mantle of the Earth behave as a linear, isotropic, high- $Q$ system.

(2) The spatial character of sources at a wide range of depths seems to be that of a finite shear dislocation. The size of the dislocation depends on the source's depth.

(3) The temporal character of shallow shocks accords with that of a unit-step function. That of deep shocks may contain a delta-function component. Time functions of deep shocks may also carry a signature of the region in which they occur (Figure 18).

(4) A dip-slip orientation is common to most analyzed deep shocks. (Table 1). Two orientations are dominant: a dip-slip on a vertical fault $\left(\lambda=90^{\circ}, \delta=90^{\circ}\right)$ and a dip-slip on a fault dipping at $45^{\circ} .\left(\lambda=90^{\circ}, \delta=45^{\circ}\right)$. Our present sample tentatively suggests that the second alternative is typical of the equatorial zone $-22.5^{\circ}$ $<$ Latitude $<22.5^{\circ}$ while the first alternative is dominant elsewhere.

(5) The source's depth is recoverable from spectral modal ratios of surface waves.

\section{ACKNOWLEDGMENTS}

This research has been sponsored by the Air Force Cambridge Research Laboratories under Contract AF61 (052)-954 through the European Office of Aerospace Research, OAR, USAF, as part of the Advanced Research Projects Agency's Project VELA-UNIFORM.

We wish to thank professor David G. Harkrider of Brown University, Rhode Island, for communicating to us his results in advance of publication. Dr. Michael Shimshoni of the Weizmann Institute helped us with the programming of the body-wave travel times.

\section{REFERENCES}

Aki, K. (1960). Study of earthquake mechanism by a method of phase equalization applied to Rayleigh waves and Love waves, J. Geoph. Res. 65, 729-740.

Aki, K. (1966). Generation and propagation of $G$ waves from the Niigata earthquake of June 16, 1964, Bull. Earthq. Res. Inst. 44, 23-72, 73-88.

Alexander, S. S. (1963). Surface wave propagation in the western United States. Doctoral Dissertation, California Institute of Technology, Pasadena. 
Alsop, L. E. and J. N. Brune (1965). Observation of free oscillations excited by a deep earthquake, J. Geoph. Res. 70, 6165-6174.

Anderson, D. L., A. Ben-Menahem and C. B. Archambeau (1965). Attenuation of seismic energy in the upper mantle, J. Geoph. Res. 70, 1441-1448.

Ben-Menahem, A. (1965). Observed attenuation and $Q$ Values of seismic surface waves in the upper mantle, J. Geoph. Res. 70, 4641-4651.

Ben-Menahem, A. (1965). Source studies from isolated seismic signals, Proc. VESIAC Conference for Source Mechanism, Willow Run Labs. 7885-1-x, 85-108.

Ben-Menahem, A. and D. G. Harkrider (1964). Radiation patterns of seismic surface waves from buried dipolar point sources in a flat stratified Earth, J. Geoph. Res. 69, 2605-2620.

Ben-IMenahem, A., S. W. Smith and T. L. Teng (1965). A procedure for source studies from spectrums of Iong-period seismic body waves, Bull. Seism. Soc. Am. 55, 203-235.

Ben-Menahem, A. and M. N. Toksöz (1963). Source mechanism from spectrums of long-period surface waves, J. Geoph. Res. 68, 5207-5222.

Ben-Menahem, A. (1961). Radiation of seismic surface waves from finite moving sources, Bull. Seism. Soc. Am. 51, 401-435.

Ben-Menahem, A. and Sarva Jit Singh (1967). Figenvector Expansions of Green's Dyads and its applications to Geophysical Theory, (in press).

Brune, J. N., E. Nafe and L. E. Alsop (1961). The Polar phase shift of Surface Waves on a Sphere, Bull. Seism. Soc. Am. 51, 247-257.

Brune, J. N. (1964). Travel times, body waves and normal modes of the Earth, Bull. Seism. Soc. Am. 54, 2099-2128.

Brune, J. N. (1961). Radiation pattern of Rayleigh waves from the southeast Alaska earthquake of July 10, 1958, Pub. Dominion Obs. Ottawa 24, 373-383.

Chander, R. and J. N. Brune (1965). Radiation pattern of mantle Rayleigh waves and the source mechanism of the Hindu Kush earthquake of July 6, 1962, Bull. Seism. Soc. Am. 55, 805-820.

Evison, F. F. (1967). On the occurrence of volume change at the earthquake source, Bull. Seism. Soc. Am. 57, 9-25.

Gilman, R. (1960). Reports on some experimental long-period seismographs, Bull. Seism. Soc. Am. 50, 553-559.

Hagiwara, T. (1958). A note on the theory of the electromagnetic seismograph, Bull. Earthq. Res. Inst. 36, 139-164.

Harkrider, D. G. (1967). Surface waves in multilayered elastic media, 2. Higher mode spectra and spectral ratios from point sources in plane layered earth models, Bull. Seism. Soc. Am., (in press).

Harkrider, D. G. (1964). Surface waves in multilayered elastic media, 1. Rayleigh and Love waves from buried sources in a multilayered elastic half-space, Bull. Seism. Soc. Am. 54, 627-680.

Haskell, N. A. (1964). Radiation pattern of surface waves from point sources in a multi-layered medium, Bull. Seism. Soc. Am. 54, 377-393.

Haskell, N. A. (1963). Radiation pattern of Rayleigh waves from a fault of arbitrary dip and direction of motion in a homogeneous medium, Bull. Seism. Soc. Am. 53, 619-642.

Haskell, N. A. (1953). The Dispersion of Surface Waves in Multilayered Media, Bull. Seism. Soc. Am. 43, 17-34.

Haskell, N. A. (1962). Crustal reflections of plane $P$ and $S V$ waves, J. Geoph. Res. 67, 4751-4767.

Hedayati, A. and T. Hirasawa (1966). Mechanism of the Hindu Kush earthquake of January 28, 1964, Bull. Earthq. Res. Inst. 44, 1419-1434.

Iida, K. (1965). Earthquake magnitude, earthquake fault and source dimensions, J. of Earth Sciences, Nagoya University 13, 115-132.

Jeffreys, H, and K. E. Bullen (1958). Seismological Tables, Office of the British Association for the Advancement of Science, Burlington House, W.1, London.

Jeffreys, H. and M. Shimshoni (1964). The Times of $p P, s S, s P$ and $p S$, Geophys. J. 8, 324-337.

Kasahara, K. (1963). Waveform analysis of $S$ pulse from deep-focus earthquakes, Bull. Earthq. Res. Inst. 41, 209-216.

Press, F. (1965). Dimensions of the source region for small shallow earthquakes, Proc. VESIAC Conference for Source Mechanism, Willow Run Labs. 7885-1-x, 155-163.

Ritsema, A. R. (1958). ( $i-\Delta)$-Curves for bodily seismic waves of any focal depth, Meteorol. and Geophys. Inst., Djakarta, Verhandelingen 54, 1-10.

Ritsema, A. R. (1964). Some reliable fault plane solutions, Pure and App. Geophys. 59, 58-74. 
Satô, Y. (1955). Analysis of dispersed surface waves by means of Fourier transform, Bull. Earthq. Res. Inst. 33, 33-48.

Shimshoni, M. (1966). The times of PP, SS, SP and PS, Geophys. J. 11, 477-483.

Steinhart, J. S. and R. P. Meyer (1961). Explosion studies of continental structure, Carnegie Inst. of Washington Pub. 622, 347-351.

Teng, T. L. and A. Ben-Menahem (1965). Mechanism of deep earthquakes from spectrums of isolated body-wave signals, J. Geoph. Res. 70, 5157-5170.

Toksöz, M. N. and A. Ben-Menahem (1963). Velocities of mantle Love and Rayleigh waves over multiple paths, Bull. Seism. Soc. Am. 53, 741-764.

Toksöz, M. N., A. Ben-Menahem and D. G. Harkrider (1964). Determination of source parameters of explosions and earthquakes by amplitude equalization of seismic surface waves, $J$. Geoph. Res. 69, $4355-4366$.

Travis, H. S. (1965). Interpolated Jeffreys and Bullen seismological tables, Technical Report No. 65-35, The Geotechnical Corp.

Tukey, J. (1959). Equalization and pulse shaping techniques applied to the determination of initial sense of Rayleigh waves, Report on a Panel of Seismic Improvement, Appendix 9 (Chairman, L. V. Berkner).

Department of Applied Mathematics

The Weizmann Institute of Science

ReHOVOT, IsRAEL

Manuscript received March 7, 1968. 